\title{
Present and Future Sustainability Development of 3D Metal Printing
}

\author{
Austin Anderson ${ }^{1}$, Selso Gallegos ${ }^{1}$, Behnaz Rezaie ${ }^{{ }^{*}}$, Fardad Azarmi ${ }^{2}$
}

\author{
${ }^{1}$ University of Idaho, USA \\ ${ }^{2}$ North Dakota State University, USA \\ *Corresponding Author: Rezaie@uidaho.edu
}

Citation: Anderson, A., Gallegos, S., Rezaie, B. and Azarmi, F. (2021). Present and Future Sustainability Development of 3D Metal Printing. European Journal of Sustainable Development Research, 5(3), em0168. https://doi.org/10.21601/ejosdr/11132

ARTICLE INFO

Received: 13 Apr. 2021

Accepted: 23 Jul. 2021

\begin{abstract}
Additive manufacturing (AM), also known as 3D printing is a relatively new concept and promising technology for industrial production. It is important to investigate the environmental impact of the AM process in light of the environmental critical situation of the Earth. The elimination of some costly prefabrication processes such as molding or post-fabrication stages such as machining and welding required in traditional manufacturing methods favor the AM process and provide beneficial economic advantages. Furthermore, the reduction of manufacturing steps contributes to environmental protection through fewer operations, less material, and energy consumption, and reduced transportation. This study is a review for the assessment of environmental impact and life cycle of some well-known AM technologies for manufacturing metallic parts and components. The fabrication of a pump impeller is simulated through a well-known metal production AM technology and casting process for direct comparison. Life Cycle Assessment (LCA) is applied to measure the environmental impact in five different stages of pump impeller lifetime with the two different fabrication processes. AM compared to casting has an environmental impact reduction potential of $15 \%, 20 \%, 65 \%$, $20 \%$, and $10 \%$ respectively in Global Warming Potential (GWP), Acidifications Potential (AP), Water Aquatic Eco-toxicity Potential (FAETP), Human Toxicity Potential (HTP), and Stratospheric Ozone Depletion (ODP). Using hydroelectricity and renewable electricity mitigate the environmental impact of the AM process in premanufacturing and manufacturing stages temporarily until the advancement of AM technology for consuming less energy. Recommendations for future research to enhance the environmental sustainability of the AM process is proposed as outcomes of this study.
\end{abstract}

Keywords: metal additive manufacturing sustainability, 3D printing life cycle analysis, additive manufacturing environmental impact, casting sustainability analysis, laser metal deposition environmental effect

\section{INTRODUCTION}

Innovative ideas demand a quick and inexpensive prototyping method to be competitive in the market. AM is a progessive technology that started a revolution in the manufacturing industry (Berman, 2012). Parts and components are fabricated layer by layer onto a build platform in AM technology. In metal printing, a heat source is used to melt feedstock powders for the formation (deposition) of a layer which rapidly solidifies before deposition of the next layer (Herzog et al., 2016). Components with very complex geometries are manufactured using AM which is otherwise impossible to produce with conventional manufacturing methods; and Assemblies requiring several parts separately built and assembled while that can be produced as one component using AM (Herzog et al., 2016). As manufacturing is shifted from conventional to AM, supply chains are expected to shorten due to reduced tooling requirements and localized production replacing centralized manufacturing (Gebler et al., 2014; Petrovic et al., 2011). Another important characteristic of $\mathrm{AM}$ is the reduced likelihood of human error during manufacturing because of AM machines using digital computer-aided design (CAD) files to provide the manufacturing specifications (Ford and Despeisse, 2016). AM alters the design landscape by using digital CAD files which facilitate communication between design engineers and manufacturers, known as Direct Digital Manufacturing (DDM) (Chen et al., 2015). DDM, with its ability to locally manufacture parts on demand from stored CAD files, reduces suppliers' demands that result in less transportation and ultimately less energy consumption and lower emissions (Chen et al., 2015).

The use of highly optimized tools and components produced using AM technology boosts the efficiency of other manufacturing processes and allows the development of new hybrid processes. These hybrid processes lead to further 
customization of complex tooling that requires fewer parts and assemblies, thus reduce the environmental burden (Despeisse et al., 2017). This characteristic of AM alters business models by shifting the focus towards building durable, high-quality parts with less complexity to re-manufacture, such as a modular design that has easily upgradeable (Despeisse et al., 2017). AM machines that spend a majority of time idling waste significant amounts of energy and increases environmental concerns (Faludi et al., 2015). Comparison of low machine usage to high machine usage showed a lowering of environmental impact per component built by a factor of ten (Faludi et al., 2015).

This characteristic of the AM process has provided more liberty for designers, particularly for high value, low volume industries such as aerospace and medical (Gebler et al., 2014). It is presumed that AM is the potential to reduce economic costs by $170-593$ billion US $\$$ and the primary energy supply by $2.54-9.30 \mathrm{EJ}$ and $\mathrm{CO}_{2}$ emissions by $130.5-525.5 \mathrm{Mt}$ by 2025 (Gebler et al., 2014).

LCA is used to quantify the environmental effects of processes, products, and services. Several LCAs regarding AM have been performed. Mami et al. explored the environmental and economic aspects of AM concerning the aeronautics sector (Mami et al., 2017). They propose an approach based upon industries' environmental targets and provide a recommendation for the eco-efficient application of AM technology. In their methodology, they derive a weighting factor between multiple normalized impact scores and the industry's target goal. Conventional manufacturing of an aerospace component was compared with a normal AM process as well as a topology optimized AM component. They found that weight reduction (342 grams to 274 grams) from an optimized AM manufactured component made it the superior technology from an environmental perspective.

Faludi et al. (2017) extended the knowledge of AM environmental impacts by using an LCA to determine whether the environmental contributions of the raw material, printer hardware, or the process energy consumption were more influencing. Their test specimen was a complex turbine manufactured using selective laser melting (SLM) with a cradle to cradle scope. They determined that electrical demands encompassed around $80 \%$ of embodied energy and around $66 \%-75 \%$ of the other environmental impact metrics. The electric demand was also sensitive to utilization rates of the machine, with more idle time resulting in more electrical energy.

Walachowicz et al. (2017) compared laser beam melting with traditional manufacturing methods (CNC machining) by repairing a burner for an industrial-scale gas turbine. They also explore recycling options on environmental impact. They recorded the electricity consumption for the repair process as well as all other material flows. AM was found to be much more environmentally friendly due to its higher material efficiency. The conventional repair process wasted three times the mass of the AM repair process.

Turbine blades manufactured using SLM, Investment Casting, and Precision Machining were compared via LCA (Torres-Carillo et al., 2020). Their investigation showed a decrease of $\mathrm{CO}_{2}$ emissions from 7.32 tons to 7.02 tons by switching to the AM process.

Bekker and Verlinden (2018) conducted an LCA of wire arc AM was compared to $\mathrm{CNC}$ milling and green sand casting using stainless steel as the material. They performed a cradle-togate LCA using empirical measurements of a wire and arc additive manufacturing (WAAM) process. They concluded that $\mathrm{AM}$ is equal to both the processes from an environmental standpoint when it has a $75 \%$ material utilization efficiency.

Böckin and Tillman (2019) conducted an LCA using powder bed fusion technology for the automotive industry by considering a complete product lifecycle in comparison with conventional manufacturing. They showed weight reduction of an AM part played an important role, suggesting that the lower weight of produced products resulted in significant environmental benefits.

This study presents the fundamental methods of the AM processes and describes different types of available AM technology with a focus on the exploration of environmental and economic aspects of the technology. Then, using LCA methodology, a comparative evaluation of a conventional manufacturing process and a well-known AM technology is investigated by fabrication of a metallic component. Comparison of the LCA outcomes for two processes is discussed and validated with other studies and methods for improving each process are suggested. Finally, future research for advancing the AM process is suggested concerning environmental sustainability. The present work is an introduction based on past studies for environmental sustainability examination of the AM process in general and is a foundation for future studies.

\section{METAL ADDITIVE MANUFACTURING}

American Society for Testing and Materials (ASTM) recognizes seven additive manufacturing technologies for 3D printing of parts and components (ASTM F2792: Standard Terminology for Additive Manufacturing Technologies, 2013). A 3D model developed by CAD software is exported to the printing machine in the first step of AM process. This model is sliced into many individual layers to be fabricated during printing (Herzog et al., 2016). Different technologies can be used to form the product layer by layer according to the CAD model. There are different ways to build up layers such as deposition, rolling, or spraying depending on the AM technology. Each technology has its characteristics, advantages, disadvantages, and applications. However, metal AM generally is compiled into three main categories (Frazier, 2014):

- powder bed systems (PBS),

- powder feed systems (PFS),

- $\quad$ wire feed systems (WFS)

These category identifications are not standardized in research and industry; however, the metal AM technology is the same among all methods. Regardless of technology type in metal AM, one of the main concerns is reduction of residual stress formation and control of microstructural characteristics during printing which can determine service life and 
performance of 3D printed metal parts and components (Azarmi and Sevostianov, 2020). Proper energy input is essential for the success of the powders feed methods since reduced part density in the form of voids appear in materials when the energy input during manufacturing is too low (Herzog et al., 2016). Conversely, too much energy input reduces density by entrapping gas within the part during the melting process (Herzog et al., 2016). Besides, the surface quality of manufactured parts is essential to the success of many components. Factors for powders based systems that affect surface quality include the type of alloy, powders shape and size, energy source focal point size, and feed rates (Shamsaei et al., 2015).

\section{Powder Bed Systems}

PBS construct components by raking a thin layer of metallic powder across a work surface and melting the powders in the specified geometry of the final solidified part (Herzog et al., 2016). Typical heat sources for melting powders are laser beams or electron beams. They require a support structure for heat dissipation as well as for the structure of the part (Herzog et al., 2016). The high levels of heat dissipation require preheating $\left(200^{\circ} \mathrm{C}-500^{\circ} \mathrm{C}\right)$ of the bed to reduce warping (Herzog et al., 2016). In comparison to other metal AM processes, PBS build volume is less than $0.03 \mathrm{~m}^{3}$, that results in a limitation of the size of components (Frazier, 2014).

PBS lasers have wavelengths of infra-red range with spot sizes between 50-180 $\mu \mathrm{m}$, and laser beam melting (LBM) layer thicknesses are around 20-100 $\mu \mathrm{m}$ (Herzog et al., 2016). The choice of laser has a significant impact on the quality of the product and it depends on the absorptivity of materials for melting the desired powders sufficiently at a given feed rate (Gu et al., 2012). Inert gases such as Nitrogen or Argon are used to aid in keeping oxygen levels low for preventing any harmful chemical reactions (Herzog et al., 2016).

\section{Powder Feed Systems}

PFS's utilize a nozzle to spray powders onto a surface to create the desired geometry instead of raking the powders across the surface like PBS (Frazier, 2014). As the powders are spayed, a heat source melts the powders similar to PBS (Frazier, 2014). The printing process is carried out by a raster motion of the laser beam in a rectangular pattern across the stationary workpiece (Herzog et al., 2016). Inert gasses in PFS are Helium and Argon to protect against oxidation (Peng et al., 2018).

PFS often have larger build volumes like the Optomec 850R-unit of $1.2 \mathrm{~m}^{3}$ compared to PBS (Frazier, 2014). Build rates of $300 \mathrm{~cm}^{3} / \mathrm{h}$ (higher than PBS) are achieved using a layer thickness between $40 \mu \mathrm{m}$ to $1 \mathrm{~mm}$ (Herzog et al., 2016). In addition to building new components PFS allows for rebuilding or repairing of existing products (Frazier, 2014). The subsets of PFS include (Herzog et al., 2016):

- Laser metal deposition (LMD)

- Electron beam melting

- Plasma arc beam melting.

The major focus of this research is on LMD. However, some other AM technologies have also been discussed in this study. A high-power laser source provides the required energy for melting metallic powders in the LMD process. There are many different aliases and commercialized variations of this technology such as direct metal deposition, laser direct casting, laser engineered net shaping, laser cladding, and laser deposition welding. These different names are adopted by various institutions and companies while they are essentially the same technique of using a laser to melt and deposit powders into a substrate (Shamsaei et al., 2015).

\section{Wire Feed Systems}

WFS is extremely similar to PFS with a metallic wire instead of the metallic powders being the main difference (Frazier, 2014). Due to the large availability and low price of wire, WFS is less expensive than powder-based systems (DebRoy et al., 2018). WFS is capable of high build rates, associated with large molten pools, and large build volumes in comparison to PFS and PBS (DebRoy et al., 2018). Because of rough surfaces, WFS often require post-process machining to achieve the desired static and dynamic qualities (DebRoy et al., 2018). WFS energy sources are divided into three subgroups like in PFS (Ding et al., 2015):

- Electron beam-based

- Laser beam based

- Electrical Arc based

The most common energy source for WFS technology is the laser beam due to its high precision. However, it is an inefficient technology (2-5\% efficiency) in terms of energy consumption. In comparison, the efficiency of electron beam sources is approximately $15-20 \%$ but it requires high vacuum working environments, which can limit its application (Ding et al., 2015). Metal arc welding has considerably higher efficiencies than both laser beam and electron energy sources, sometimes reaching up to 90\% (Ding et al., 2015). However, the higher accuracy of laser beam technology makes it more demanding instead of its lower efficiency.

\section{ECONOMICS ASPECTS OF ADDITIVE MANUFACTURING}

The AM technology has the unique capability of preparing industrial products almost ready to the point of final use directly after fabrication. Consequently, parts and components fabricated by this technique were produced at minimum inventory because of being an "On-demand" process. A noticeable reduction in waste of materials and time were among other reasons for commercialization of this technology. It resulted in drastic increase in utilization of AM technology by industry in two decades between 1990 until 2010. The advancement of new AM technogies resulted in the same growth rate in 3 years (2010-2013) (Srivatsan and Sudarshan, 2015). The predictions show that the rapid growth rate of AM technology is going to countinue in future decades. A recent analysis of the market capabilities of AM predicts that the AM industry will reach a market size of $\$ 50$ billion between 2029 and 2031 and $\$ 100$ billion by 2044 (Tofail et al., 2018). The majority of these markets are expected to be developed in the aerospace, automotive, and healthcare industries (Yakout et al., 2018). Additionally, it is expected that AM technology to 
highly implement in the manufacturing of tools and molds with internal cooling by optimized channels that reduce thermal stress in loading dies which results in higher production rates (Yakout et al., 2018). As the technology further develops and penetrates the market, economies of scale are a reality, meaning that larger volume productions of materials using AM may be economically feasible (Baumers et al., 2016). AM is foreseen to rapidly alter the manufacturing market from manual engineer-to-order production to a customer individual mass-production market (Oettmeier and Hofmann, 2016). The implementation of AM into the market will integrate customers more closely to the manufacturers' supply chain by reducing lead times, low volume products that would often take significant amounts of time to manufacture (Oettmeier and Hofmann, 2016). On the otherhand utilization of AM technology ususally does not require significant investment in infrastructure, space, tools, and logistics which can bring additional economical advatages over the traditional manufacturing processes (Levy et al., 2003).

\section{ENVIRONMENTAL ASPECTS OF ADDITIVE MANUFACTURING}

\section{Consumption Reduction}

Compared to traditional methods in which material is removed from a larger block, AM fabrication is considerably less wasteful since parts are built layer by layer (Ford and Despeisse, 2016). AM technology has less environmental impact than traditional machining processes because little metal debris or chips are produced during the fabrication process (Serres et al., 2011). The majority (approximately 90\%) of environmental impact in AM technology is a result of the atomization process required for feedstock powders manufacturing. The atomization process in powder manufacturing consumes high energy but results in small amounts of waste since it is a semi closed-loop processing cycle (Serres et al., 2011).

The major sustainable benefits of utilization of AM technology are (Ford and Despeisse, 2016):

- More efficient designed products

- Shorter supply chains, localized production, and condensed transportation routes.

Furthermore, these environmental advantages of AM technology have a huge impact on strengthening the local economy and social value (Ford and Despeisse, 2016).

The Solid Freeform Fabrication (SFF) and Direct Metal Deposition (DMD) as a die and mold manufacturing processes have high potential to drastically reduce conventional supply chain operations such as casting, forging, and machining, which results in dropping product lead times as well as the fossil fuel consumption, pollution, and resource wastes (Morrow et al., 2007). In a study by Morrow et al., three case studies were considered: a simple injection mold insert, a mirror fixture, and stamping die used in the auto industry for comparison of DMD and Computer Numerical Control (CNC) methods. The biggest defining parameter for energy consumption was the solid-to-volume cavity ratio, with low ratios tending to favor DMD processes while high ratios were more appropriate for CNC machining. The outcomes suggested that part geometry played a critical role in the comparison of the technologies, with more complex parts DMD is environmentally more favorable. For the production of parts with low solid-to-cavity volume ratios, AM is more efficient in terms of materials, time, and energy compared to the milling process. Solid-to-cavity volume ratio is the ratio of component mass to the mass of the minimally bounding volume of the component assuming it is completely solid and composed of the identical material as the component (Morrow et al., 2007).

\section{Resource Protection}

Typical options for material disposal include recycling, reusing, repairing, or placing parts of the product in a landfill. Worldwide waste has been predicted to reach 2.2 billion tons by 2025, resulting in significant problems (Chan, 2016). Unfortunately, despite expanded recycling networks, the human population has been increasing its resource consumption year over year (Catlin and Wang, 2013). One of the key advantages of AM is the recycling capability of the product at the end of life (EOL). Recycling materials is crucial and has a huge impact on protecting resources as well as saving energy and water from reduced mining of new materials. Additionally, reducing waste allows the landfills to last longer. Practice for using recycled materials are as follows:

\section{Recycled powders}

The material waste, emissions, and cost are reduced by using more recycled materials instead of unused original feedstock powders (Villamil et al., 2018). However, some studies have shown that the recycled powders can oftentimes contain incorrect particle sizes, which needed further refinement for the powders to be appropriate for re-use in fabrication (Villamil et al., 2018). In certain industries, particularly aerospace, the component demands high-quality materials, which limits the use of re-used powders. Comparison between different manufacturing processes indicated that (Villamil et al., 2018):

- Approximately $87 \%$ of the materials in conventional manufacturing processes end up as waste while AM technologies such as LMD have almost no waste.

- A large amount ( $70 \%)$ of waste powder from some manufacturing processes such as EBM cannot be reused without proper treatment and recycling process.

- There is additional waste from the post-processing due to material removal.

The average mass ratio of initial material to the final product is reported to be in the range of $12: 1$ to $25: 1$ using traditional processes for manufacturing aerospace components made from titanium, while for AM processes this ratio is much lower, around 1.5:1 (Villamil et al., 2018). Furthermore, the use of topology optimization such as building honeycomb structures or internal cooling channels significantly cuts down on the weight of components, which is particularly attractive for the aerospace industry (Villamil et al., 2018). However, the requirement of having a support structure to stabilize and fix objects during the printing process may result in the production of some waste materials during the AM process. Currently, the possibility of proper 
Table 1. Advantages and disadvantages of metal AM manufacturing

Advantages of AM manufacturing $\quad$ Disadvantages of AM manufacturing

Multiple materials are deposited in a continuous spray within a single Low production volumes limit the technology only to be applicable for component, allowing for new hybrid material compositions (Gu et al., the production of highly customized products that are expensive and 2012). difficult to manufacture via traditional methods (Ford and Despeisse, 2016).

Wear-resistant alloys are easily deposited onto tool surfaces that lead Microstructural and mechanical anisotropy results in weakened to a significant extension of useful life for metal tooling (Morrow et al., properties within the direction normal to the plane of deposition 2007). (Frazier, 2014).

A high rate of material recovery (approx. 97\%) compared to traditional Rapid heating and melting negatively affect fatigue characteristics methods (Peng et al., 2018). (Frazier, 2014).

Fabrication of highly complex geometries products that are not possible otherwise (Peng et al., 2018).

When properly processed, the static mechanical properties of metal AM materials are comparable to conventionally fabricated metallic Post-processing may require depending upon the requirements of the component (Gu et al., 2012).

components (Frazier, 2014).

Smaller and more localized supply chains leading to shorter lead times Intellectual property and copyright issues have the potential to arise and less capital required (Peng et al., 2018). from the ability to easily distribute and share digital designs (Oettmeier and Hofmann, 2016).

Opportunity for the refurbishing of parts that would otherwise be un- High energy investment required to operate machinery (Huang et al., repairable, such as turbine blades, bearing seals, and shafts (Gu et al., 2012).

2012).

Digital designs easily are shared and edited using modern CAD

software (Ford and Despeisse, 2016).

AM processes require no cutting fluids (Huang et al., 2012).

No significant tooling or molding process is required for AM process

(Ford and Despeisse, 2016).

AM allows for further use of aging products by building retrofits and

extending the operational life of equipment (Stock and Seliger, 2016).

recycling and reuse of support material is under investigation by industry (Villamil et al., 2018).

\section{Recycled products}

It is feasible to utilize both $\mathrm{AM}$ and traditional manufacturing technologies to take EOL parts and efficiently produce new parts in order to bypass the recycling stage. With this strategy, new products are fabricated from old products that possess similar mechanical properties to conventionally processed products (Le et al., 2017). Appropriate utilization of this approach can significantly reduce material and energy consumption during the manufacturing process (Le et al., 2017). Comparison between the primary energy usage of AM versus traditional manufacturing processes used in the refurbishing of EOL parts showed that the conventional repair process required significantly higher energy than the AM repair process, particularly in the number of required materials.

\section{Advantages and Disadvantages}

The application of AM technology to produce metallic parts and components exhibit many advantages over using traditional manufacturing techniques. Some of those advantages are small while others are considered game changers and have a significant effect on the manufacturing of specific products. Many of these advantages and disadvantages are studied to either further their advancement or mitigate their weaknesses. Table 1 presents the pros and cons of metal AM.

\section{ADDITIVE MANUFACTURING SUSTAINABILITY ADVANCEMENT}

Although the field of metal processing via AM technology is relatively young, there is always an effort to continually improve energy and materials efficiency for LMD technology. Various approaches are currently being researched to work towards enhancing AM technology, some are discussed below.

One of the drawbacks of LMD is low energy efficiency. One method of increasing efficiency is increasing the deposition speed by supplementing inductive assisted laser cladding (Leyens and Beyer, 2014). Inductive heating is added to the laser process and compensates for rapid heat loss from the laser. The use of inductive heating during manufacturing increases deposition rates by a factor of approximately 2-2.5 while doubling the overall energy efficiency of the process (Leyens and Beyer, 2014). Furthermore, adding the induction heat reduces spatial temperature gradients in the materials, which results in more durable structures.

The use of mechanical milling to produce feedstock powders for the AM process makes it possible to develop a sustainable powders production route by making powders from a variety of materials chips with different sizes (Fullenwider et al., 2019). Due to the nature of mechanical milling, there is no requirement for high temperatures, which allows for significantly lower energy consumption in comparison to traditional atomization processes (Fullenwider et al., 2019). The powders are formed using a novel two-stage mechanical milling approach and have near-spherical morphology and particle diameters of $38-150 \mu \mathrm{m}$, making 
them comparable to conventionally produced powders (Fullenwider et al., 2019).

The process chambers of the AM technology is improved with access to higher quality chamber seals, which reduces the consumed process gasses to generate the inert process atmosphere (Kellens et al., 2014). The accurate control of subsystems within the machine yields energy savings by turning off various parts of the machine in standby mode and downtime. A final design improvement is implemented in a variable volume process chamber, where the height, width, and depth of the chamber are adjusted to suit the requirement of the product for manufacturing and resulted in less energy consumption (Kellens et al., 2014).

Efficient powders heating leads to less energy consumption. Improving laser technology results in an efficiency increase of the AM process, since lasers contribute to significant energy demand (Pinkerton, 2016). Consequently, using advanced lasers with high wall-plug efficiency mitigates the significant energy consumption.

\section{METHODOLOGY}

LCAs is a tool for the measurement and analysis of effects of a process, product, or service on the environment such as greenhouse gas emissions, ozone depletion, smog creation, eutrophication, acidification, depletion of resources, water use, land use, and many other aspects that are quantified and understood through impact assessments results from LCAs (Rebitzer et al., 2004). Interpretation of results follows the four basic elements (goal, scope, inventory analysis, and impact assessment) and are defined for LMD machines in this study.

There are several unrestricted and commercial LCA Software packages with databases available such as $\mathrm{GaBi}$, SimaPro, and openLCA. In this study, openLCA is used since its associated databases cover the presented case study. Furthemrore, obtaining data from primary sources was not available due to lack of equipment. Although the data sets in openLCA are based mainly on Europe, most of the data points are a global reference from the selected data sets ("LCA data | openLCA.org,”). Because of that Germany is considered as the geographical area for the case study.

LCA aims to quantify the consumed energy, released emissions, and environmental impacts of LMD manufactured impeller and casting manufactured impeller during 5 stages of pre-manufacturing, manufacturing, use, transportation, and EOL. The service stage of the impeller is not considered because the impeller rotation environmental impacts are negligible. Although post-processing sometimes is required to achieve a high-quality surface finish, it is not considered a requirement of the LMD process like it is for the casting process. To measure environmental impact on water, air, and soil GWP, AP, FAETP, HTP, and ODP are among the environmental impact indicators used to quantify the environmental impacts of the two processes.

\section{CASE STUDY}

The analysis of the environmental impacts of manufacturing a stainless-steel pump impeller using LMD technology in comparison with the casting method as a conventional process is the main goal of the LCA in this study. The impeller in the pump increases the pressure of the fluid through centrifugal force. The scope of this LCA is premanufacturing, manufacturing and use, transportation, and EOL. The LCA is used as a tool for this investigation with the functional unit being 1 produced pump impeller of a mass of $10.79 \mathrm{~kg}$. The dimension and mass properties of the impeller are defined in Figure 1. While there are other aspects of both the AM and conventional process that are considered in this study. For simplicity, several variables are considered negligible for both processes.

This LCA has a goal of demonstrating how the LCA process aids in identifying the environmental impacts of manufacturing the impeller via LMD processes in comparison to a conventional manufacturing process such as casting. The direct comparison of methods allows for the areas of greatest and smallest environmental impact to be identified for future improvement and understanding.

\section{IMPLICATION OF THE LIFE CYCLE ASSESSMENT}

The energy and materials inputs and outputs for both fabrication processes of $\mathrm{AM}$ and casting are presented in Figure 2.

\section{Life Cycle Inventory}

Figures 3 and 4 illustrate the LMD and casting processes in different stages of life for the pump impeller, used for LCA. These figures show energy and materials flow in both LMD and casting processes for impeller fabrication. It must be noted that none of the processes is a closed-loop.

\section{Pre-manufacturing}

Generally, the pre-manufacturing stage of an LMD process includes mining and extraction of the raw materials in addition to the production of the metallic powders. a large variety of metals, including tool steel, stainless steel, titanium, titanium alloys, aluminum casting alloys, nickel-based superalloys, cobalt-chromium alloys, gold, and silver can be used as feedstock materials for LMD technology (Seifi et al., 2016). The mining and smelting of these materials have been fairly well documented and its environmental impacts are generally understood (Kosai and Yamasue, 2019). The environmental effects of mining are substantial and thus recycling materials should be strongly considered during the pre-manufacturing process due to economic and environmental considerations (Sverdrup et al., 2017). The powder formation process is generally referred to as the atomization process. The basic principle of the atomization process involves a stream of molten metal being rapidly disintegrated and cooled by materials into individual particles (Pinkerton and Li, 2003). Various techniques such as water, gas, centrifugal, vacuum, 


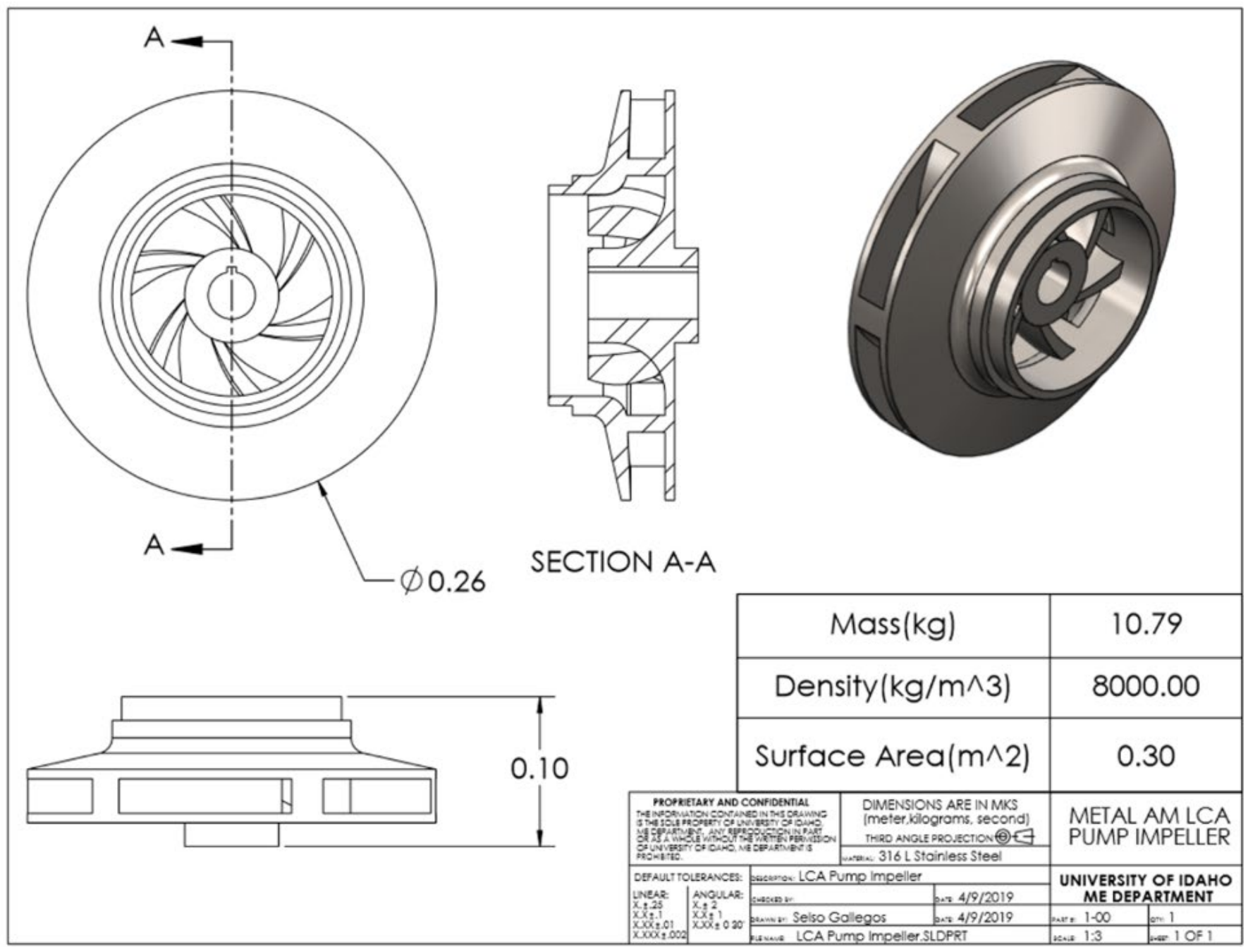

Figure 1. Drawing of pump impeller used for analysis
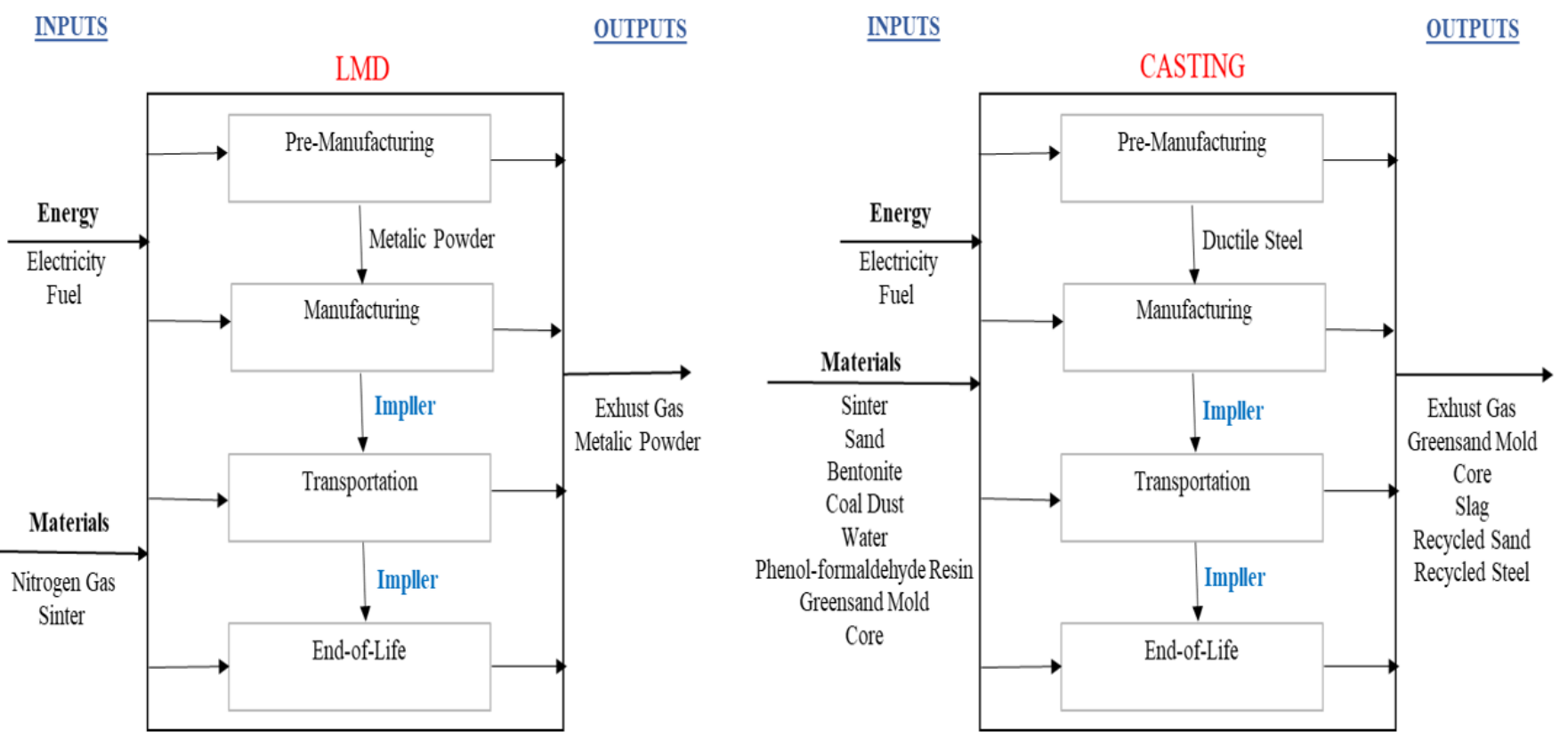

Figure 2. System boundaries for AM and casting processes 


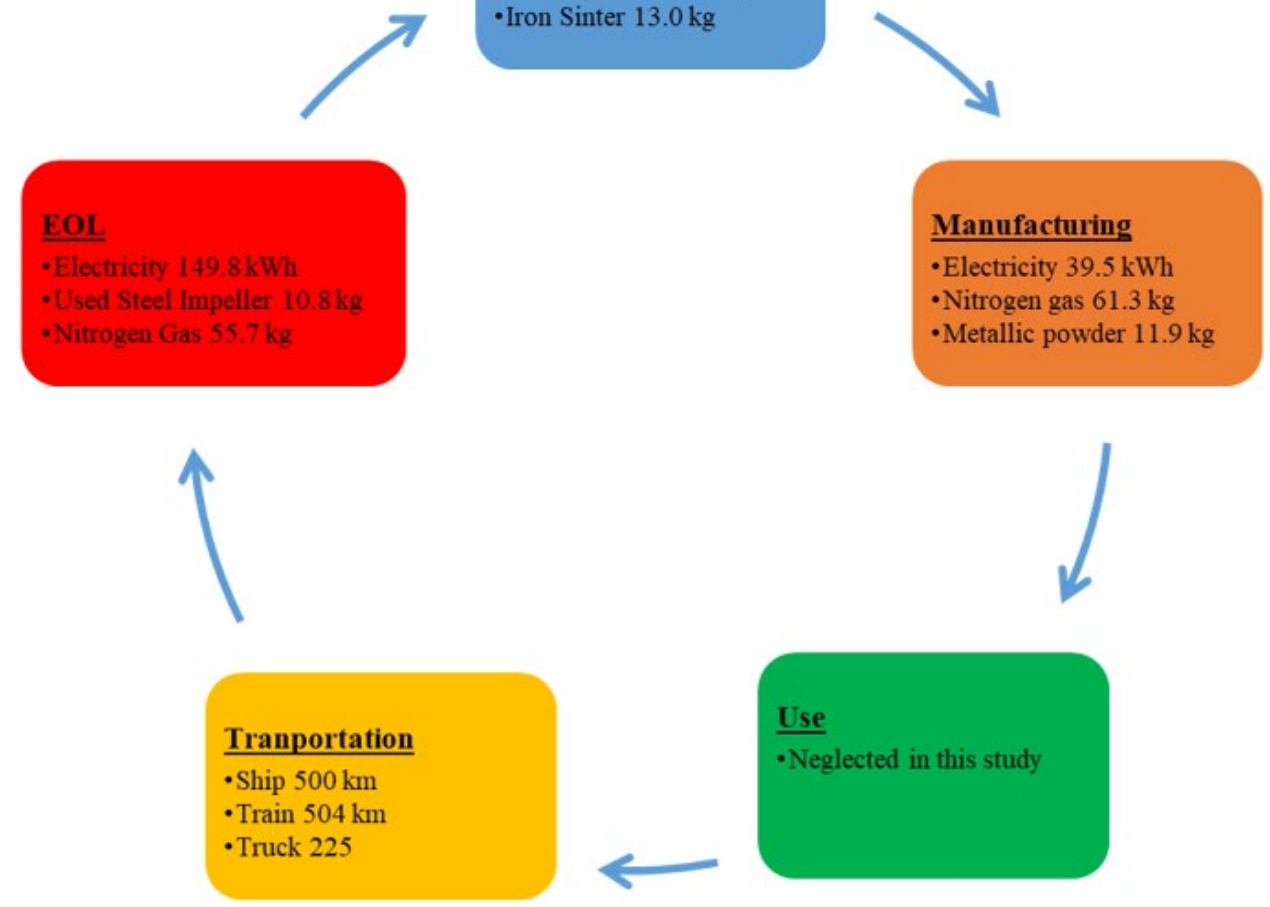

Figure 3. Summary of inputs for each stage of the LMD process
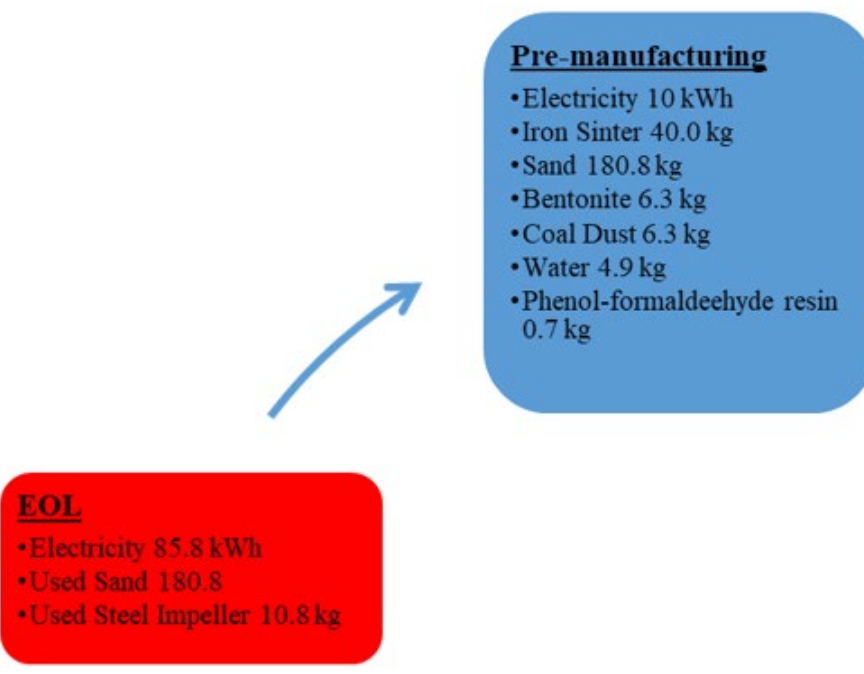

\section{Manufacturing}

-Electricity $6.3 \mathrm{kWh}$

- Greensand mold $126.3 \mathrm{~kg}$

- Core $67.9 \mathrm{~kg}$

•Ductile Steel $21.7 \mathrm{~kg}$
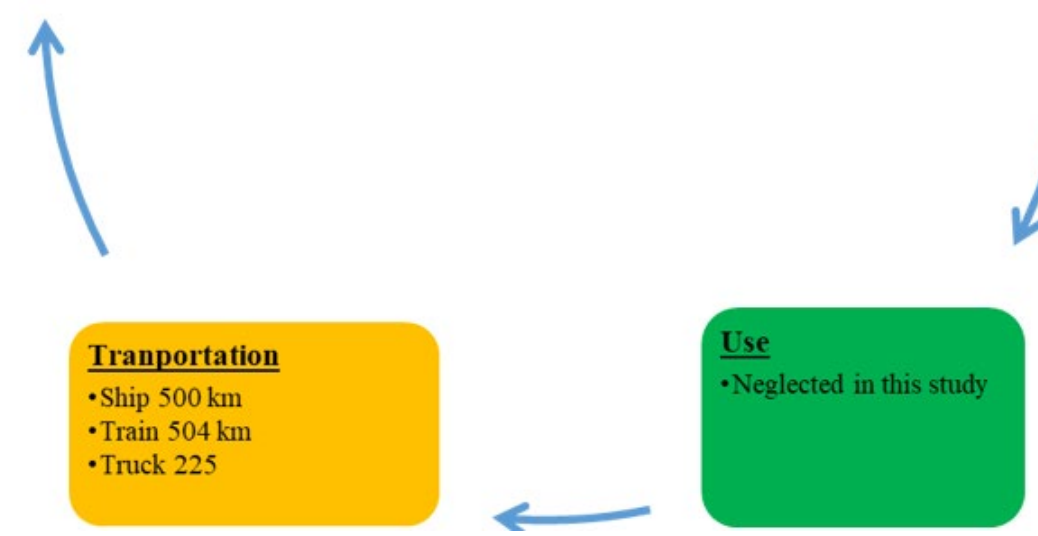

Figure 4. Summary of life cycle inputs for the casting process 
Table 2. Pump impeller pre-manufacturing inputs/outputs for LMD

\begin{tabular}{ccccc}
\hline \multicolumn{7}{c}{ Pre-Manufacturing LMD } & & Reference \\
\hline Input & Unit & Amount/Unit & Total Amount & (Paris et al., 2016) \\
\hline Electricity (Atomization) & $\mathrm{kWh}$ & 6.60 & 67.15 & (Paris et al., 2016) \\
\hline Nitrogen Gas & $\mathrm{kg}$ & 5.17 & 13.04 & (Sun et al., 2016) \\
\hline Sinter & $\mathrm{kg}$ & 13.04 & Total Amount & \\
\hline Output & Unit & Amount/Unit & 11.86 \\
\hline Metallic Powders & $\mathrm{kg}$ & 11.86 & &
\end{tabular}

Table 3. Pump impeller pre-manufacturing inputs/outputs for the casting process estimated (Yilmaz et al., 2015)

\begin{tabular}{ccc}
\hline \multicolumn{3}{c}{ Pre-Manufacturing Casting } \\
\hline Input & Unit & Total Amount \\
\hline Sinter & $\mathrm{kg}$ & 40 \\
\hline Electricity (mold making) & $\mathrm{kWh}$ & 6.85 \\
\hline Electricity (core preparation) & $\mathrm{kWh}$ & 3.2 \\
\hline Sand & $\mathrm{kg}$ & 180.8 \\
\hline Bentonite & $\mathrm{kg}$ & 6.3 \\
\hline Coal Dust & $\mathrm{kg}$ & 6.3 \\
\hline Water & $\mathrm{kg}$ & 4.85 \\
\hline Phenol-formaldehyde resin & $\mathrm{kg}$ & 2.6 \\
\hline Output & Unit & Total Amount \\
\hline Ductile Steel & $\mathrm{kg}$ & 21.73 \\
\hline Greensand Mold & $\mathrm{kg}$ & 126.3 \\
\hline Core & $\mathrm{kg}$ & 67.9 \\
\hline
\end{tabular}

and ultrasonic atomization are used (Pinkerton and Li, 2003). Water and gas atomization is the most common technique used in industry (Pinkerton and $\mathrm{Li}, 2003$ ). Electrical energy is the major source utilized for heating materials in all premanufacturing techniques.

A couple of assumptions are required for better organization of the results:

First: the input of the raw materials for the powders atomization processes are sintered Iron $(\mathrm{Fe})$ with a global reference value from the free Ecoinvent database on openLCA (Rolf Frischknecht et al., 2007). This data includes both material and energy requirements to obtain iron sinter. The database used claimed to be validated and thus was deemed appropriate for use in this study. The materials efficiency for the atomization processes is assumed $90 \%$ efficient while the efficiency of the material for the LMD manufacturing processes is also assumed $90 \%$ efficient. These values were estimated based upon values used in literature which were very high (95-98\%), and so a more conservative $90 \%$ was thought to be more appropriate (Walachowicz et al., 2017).

Second: the electricity and nitrogen gas required to produce $1 \mathrm{~kg}$ of steel powders is the same as required for titanium (Paris et al., 2016).

Table 2 summarizes the inputs used to model the Stainless-Steel atomization processes for the LMD case study. The casting process is estimated from Yilmaz et al. by scaling their inputs down in order to achieve the required $10.79 \mathrm{~kg}$ of steel impeller (Yilmaz et al., 2015). Their casting process is assumed to be the best available technology. Similarly, the inputs for the casting process are outlined in Table 3 for the pump impeller.

\section{Manufacturing}

Generally, the most complex part of the LMD process occurs during the manufacturing stage. In this stage, the primary energy inputs are required in the following parts of the process (Sreenivasan et al., 2010):

1. Laser system.

2. Stepper motors for the machine.

3. Pre-heating of the work surface.

4. Other miscellaneous parameters such as a computer, fans, and lighting.

5. Post-processing.

The amount of energy required for manufacturing a part is depending upon the required machining time during the manufacturing process. The time required is a function of process control parameters such as laser power, laser speed, scanning pattern, hatch spacing, particle feed rate, and idle time (Thompson et al., 2015). Typical laser size is on the order of 100-5000 W with beam diameters approximately around 1 mm in size (Thompson et al., 2015). Laser speeds are typically on the order of 1 to $20 \mathrm{~mm} / \mathrm{s}$ and particle feed rates are in the range of 1 to $10 \mathrm{~g} / \mathrm{min}$ (Thompson et al., 2015). Idle time is dependent upon the scanning pattern as well as the geometry and materials of the part and range from 0 to 1000 seconds, which results in a highly variable amount of energy expenditure.

Preheating of the work surface is used to reduce laser power requirements, improve radiation absorptivity of the powders, and wettability of the substrate (Yadroitsev et al., 2013). Typically, infrared or resistive heaters are used to heat the process chamber to temperatures ranging from $80^{\circ} \mathrm{C}$ to $900^{\circ} \mathrm{C}$, depending on the materials used and desired component properties (Yadroitsev et al., 2013). Much like the atomization process, gasses such as Argon or Nitrogen are typically used.

Post-processing is often required for LMD constructed parts to achieve the desired hardness or fatigue properties (Selcuk, 2011). Annealing is often used which requires a heat treatment for up to an hour at high temperatures. One of the benefits associated with LMD is the ability to recycle unused powders during the application process. Some sprayed powders onto the workpiece do not melt by the laser beam during the printing process. A large portion of the un-melted powders can be collected and reused for the AM process. The recovery rate is estimated to be in the range of $95-98 \%$ for 3D printing of metallic materials (Ford and Despeisse, 2016).

Regarding the case study, Table 4 provides a summary of assumed variables used for the construction of the pump impeller. The mass efficiency of the powder process is assumed to be $90 \%$ (Ford and Despeisse, 2016). Laser power is highly 
Table 4. Pump impeller manufacturing inputs/outputs for LMD

\begin{tabular}{ccccc}
\hline & & Manufacturing & & Reference \\
\hline Input & Unit & Amount/Unit & Total Amount & (Paris et al., 2016) \\
\hline Electricity & $\mathrm{kWh}$ & 1 & 61.33 & (Paris et al., 2016) \\
\hline Nitrogen Gas & $\mathrm{kg}$ & 5.17 & 11.86 & (Paris et al., 2016) \\
\hline Metallic Powders & $\mathrm{kg}$ & 11.86 & Total Amount & \\
\hline Output & Unit & Amount/Unit & 10.78 & \\
\hline Pump Impeller & $\mathrm{kg}$ & 10.78 & &
\end{tabular}

Table 5. Pump impeller manufacturing inputs/outputs for casting estimated (Yilmaz et al., 2015)

\begin{tabular}{ccc}
\hline & Manufacturing & \\
\hline Input & Unit & Total Amount \\
\hline Ductile Steel & $\mathrm{kg}$ & 21.73 \\
\hline Electricity (melting) & $\mathrm{kWh}$ & 2.2 \\
\hline Electricity (casting) & $\mathrm{kWh}$ & 4.1 \\
\hline Greensand Mold & $\mathrm{kg}$ & 126.3 \\
\hline Core & $\mathrm{kg}$ & 67.9 \\
\hline Output & Unit & Total Amount \\
\hline Good Casting & $\mathrm{kg}$ & 10.79 \\
\hline Slag & $\mathrm{kg}$ & 1.3 \\
\hline Used Sand & $\mathrm{kg}$ & 180.8
\end{tabular}

dependent upon build size, speed, material, as well as other parameters such as idle time. For this reason. The average laser power used by Faludi et al. was adapted due to the similarity in part size (Faludi et al., 2017). The average power consumed is $1 \mathrm{~kW}$. The assumed particle feed rate $(0.3 \mathrm{~kg} / \mathrm{h}$ ) (Thompson et al., 2015) and powder mass $(\mathrm{m}=11.86 \mathrm{~kg})$ are used to calculate the time ( $\mathrm{t}=39.53$ hours) required to print the impeller. The Nitrogen gas consumption is assumed the same as the atomization process (Paris et al., 2016). The electricity consumed by auxiliary heating requirements, stepper motors, lights, etc. are neglected since they are small in comparison with the electricity that is consumed for manufacturing and pre-manufacturing for the purpose and scope of this LCA.

Table 5 depicts the adapted inputs for the manufacturing phase of the casting process for the pump impeller. The ductile steel produced from the pre-manufacturing stage is then melted and cast using electricity into the mold and core.

\section{Use (Service condition)}

The application or service of a product or process should include all the energy and materials input plus emissions related to the scope of the LCA. When comparing two different products or processes, the product resulting from one process may perform inherently better than another during its useful lifetime. Those results are considered when substantial information is available to accurately quantify the effect of the improved performance.

In this study, an LMD process yields a pump impeller that resulted in a well-documented improved efficiency over the same pump impeller manufactured from traditional methods. The effect is included in the use section. However, there is likely to be a great deal of uncertainty in obtaining the quantities required for analysis. In most cases, an uncertainty factor is included in processes to specify that a parameter is not $100 \%$ correct. LMD is used to repair and extend the life of components (Thompson et al., 2015). Essentially, it is assumed that there is no impact from the service stage based on the quality of the LMD and casting manufactured impellers are similar enough that there is no change in operating efficiency of the impeller during use. Assuming constant quality eliminates the need to estimate two types of wearing for 3D printed and casted impellers over the operation.

\section{Transportation}

The effect of transportation for any process varies widely depending upon the required distances between various stages in the product or process lifecycle. Typical transportation processes involve several stages.

1. Raw materials from the location of extraction to the pre-manufacturing facility.

2. Pre-manufacturing to the manufacturing facility.

3. Manufacturing facility to the distribution center for the product.

4. Shipping to customer.

5. Disposal to landfill site, recycling center, and/or repair facility.

One of the potential benefits of metal AM is its ability to allow for smaller supply chains (Peng et al., 2018). Through the AM process, the number of stages in the traditional supply chain is reduced by redesigning/designing products with fewer components and manufacturing products near the consumers (Huang et al., 2012). Powders production is accomplished using locally sourced recycled materials, thus eliminating the need for shipping materials extended distances. The LMD manufacturing facilities are constructed near atomization facilities to further limit transportation environmental effects. Therefore, five stages of transportation reduce in LMD manufacturing.

The transportation parameters for the pump impeller are summarized in Table 6. Both the LMD and casting process are assumed to experience similar transportation needs, and thus Table 6 is applicable for both processes. They are broken down into the type of shipping and life cycle. Since the majority of the data sets used in the LCA originate from Europe, the LCA and the parameters for transportation are based out of locations in Europe. Between pre-manufacturing and manufacturing, the feedstock metallic powder travels approximately $400 \mathrm{~km}$ via ship from Town Castle, the United Kingdom to Bremerhaven, Germany. After the part is manufactured in Bremerhaven, it transports via train $504 \mathrm{~km}$ to Frankfurt, Germany where it is implemented. Once the impeller reaches its EOL it ships via truck for $225 \mathrm{~km}$ from Frankfurt, Germany for recycling to the closest recycling center with the capability of recycling the impeller. 
Table 6. Pump Impeller Transportation for LMD and casting processes

\begin{tabular}{ccccc}
\hline \multicolumn{5}{c}{ Transportation } \\
\hline Transport Method & LCA Phase & Cargo(kg) & Distance(km) & Reference \\
\hline Ship & Pre-Manufacturing to Manufacturing & 11.86 & 400.00 & (Frischknecht et al., 2007) \\
\hline Train & Manufacturing to Use & 13.04 & 504.00 & (Frischknecht et al., 2007) \\
\hline Truck & Use to EOL & 10.78 & 225.00 & (Frischknecht et al., 2007) \\
\hline
\end{tabular}

Table 7. Pump impeller EOL inputs/outputs for LMD

\begin{tabular}{ccccc}
\hline & \multicolumn{5}{c}{ EOL } & & Total Amount & Reference \\
\hline Input & Unit & Amount/Unit & 10.78 & \\
\hline Steel Impeller & $\mathrm{kg}$ & 1 & 64.03 & (Paris et al., 2016) \\
\hline Electricity (Atomization) & $\mathrm{kWh}$ & 6.60 & 55.74 & $($ Paris et al., 2016) \\
\hline Nitrogen Gas & $\mathrm{kg}$ & 5.17 & Total Amount & \\
\hline Output & Unit & Amount/Unit & 9.70 & \\
\hline Metallic Powders & $\mathrm{kg}$ & 9.70 & &
\end{tabular}

\section{End of life}

Since LMD utilizes metal powders as the feedstock materials, there are typically many avenues available for recycling metal powders (Graedel et al., 2011). Due to economic incentives, the recycling of valuable metals (Fröhlich et al., 2017), as well as electronic waste, is receiving much attention. The goal of recycling within AM is the potential to create a closed-loop product life cycle, wherein the product materials at the EOL can be completely recovered for use in other products.

Home scrap represents the materials waste generated during manufacturing that is directly inserted back into the process (Graedel et al., 2011). For metal AM, this would be the powders waste from one build being reused into another process. New scrap refers to manufacturing waste of materials that have known properties and known value that is not recycled within the process but instead shipped to another facility (Graedel et al., 2011). Due to the majority of powders being recycled within the product production chain, the amount of new waste generated from metal AM is likely negligible. Old scrap is materials that have reached the product EOL and generally require more energy input to recover (Graedel et al., 2011). Functional recycling is used when old scrap is separated easily and combined with an old scrap of similar composition to create new metal in the same family of materials (Graedel et al., 2011).

When the pump impeller reaches its EOL, it is recycled back into powders that would be used for another Stainless-Steel part made by LMD. The amount of energy required to recycle 1 $\mathrm{kg}$ of Stainless Steel is $7.96 \mathrm{kWh}$ (Johnson et al., 2008). It is assumed that $90 \%$ of the impeller is recovered and turned back into stainless steel powder. The amount of nitrogen gas and electricity required for atomization of the recycled steel is assumed the same as what is used in the pre-manufacturing phase.

Table 7 outlines the inputs and outputs for the recycling process of the LMD while Table 7 indicates the EOL process for the casting operation, which was estimated from (Yilmaz et al., 2015). The cast impeller is also recycled similarly since both processes are composed of steel. The used sand is partially recovered since it can be re-used within the process. From literature, it is usually assumed that around $90 \%$ of sand can be recovered (Salonitis et al., 2016). The values in Table 8
Table 8. Pump impeller EOL inputs/outputs for casting

\begin{tabular}{ccc}
\hline & EOL & \\
\hline Input & Unit & Total Amount \\
\hline Electricity (Recycling) & $\mathrm{kWh}$ & 85.8 \\
\hline Used Sand & $\mathrm{kg}$ & 180.8 \\
\hline Steel Impeller & $\mathrm{kg}$ & 10.79 \\
\hline Output & Unit & Total Amount \\
\hline Recycled Sand & $\mathrm{kg}$ & 162.7 \\
\hline Recycled Steel & $\mathrm{kg}$ & 9.7 \\
\hline
\end{tabular}

are for a $90 \%$ recovery of steel and its sand. Further sensitivity analysis is provided to explore the effects of recycling rate on EOL impact.

\section{Impact Analysis}

The goal of Life Cycle Impact Assessment (LCIA) methods is to connect each Life Cycle Inventory (LCI) result to the selected environmental impacts (Jolliet et al., 2003). Each LCI result will affect the impact category and feed the overall LCA result. LCIAs should follow the definition and guidelines outlined in the ISO 14040 Standard. International standard ISO 14042 guides the application of the LCIA (Ryding, 1999).

It is commonly known as the Carbon Footprint or GWP of a process (Pertsova, 2007). Analyzing the GWP is important because it is a direct measure of the climate change impact a process has on the environment (US EPA). The Acidification Potential (AP) is a measure of $\mathrm{kg}$ of $\mathrm{SO}_{2}$ released into the environment by a process. AP is described as the soil and water destruction via acid rain caused by acidic air emissions released into the environment (Renou et al., 2008). FWEP analyzes the environmental impact on freshwater ecosystems caused by toxic substance emissions to the soil water and air (Rosenbaum et al., 2008). HTP is a measure of the potential harm a chemical emission has on the environment (Rosenbaum et al., 2008). FWEP and HTP are measured in kg of one, 4 -Dichlorobenzene (1,4DCB). One, $4 \mathrm{DCB}$ is an organic compound found in the atmosphere that has been classified by the EPA as a possible carcinogen that has detrimental impacts on the environment (epa.gov, 1992). ODP is measured in $\mathrm{kg}$ of Chlorofluorocarbon (CFC), which is an organic compound produced as a by-product in different manufacturing processes (Rowland, 2009). It is composed of chlorine, carbon, and fluorine needs to evaluate because its' impacts are catastrophic to the environment (Rowland, 2009). CFC reacts 
Table 9. Pump Impeller Impact Categories

\begin{tabular}{ccc}
\hline \multicolumn{2}{c}{ CML 2001 Impact Categories Implemented in Ecoinvent Database } & Unit \\
\hline Impact Categories & Name & $\mathrm{kg} \mathrm{CO2-Eq}$ \\
\hline Climate Change & Upper Limit of Net GWP & $\mathrm{kg} \mathrm{SO2-Eq}$ \\
\hline Acidification Potential & Generic & $\mathrm{kg} 1,4-\mathrm{DCB}-\mathrm{Eq}$ \\
\hline Freshwater Aquatic Ecotoxicity & FAETP 100a & $\mathrm{kg} \mathrm{1,4-DCB-Eq}$ \\
\hline Human Toxicity & HTP 100a & $\mathrm{kg}$ CFC-1-Eq \\
\hline
\end{tabular}

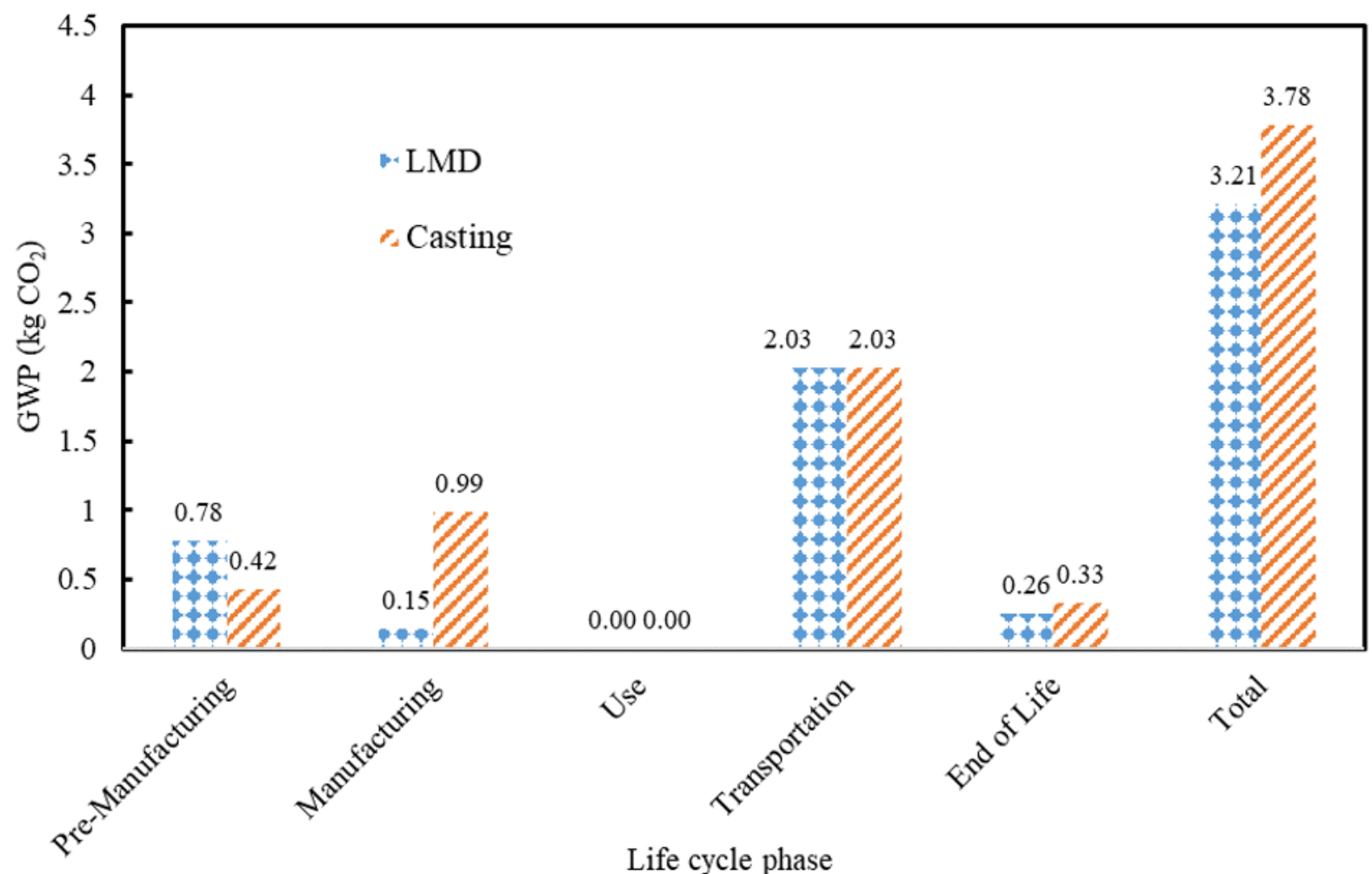

Figure 5. LMD and casting processes GWP comparison

with oxygen in the atmosphere and diminishes the ozone layer of the atmosphere in turn allowing more solar ultraviolet radiation to enter the atmosphere which impacts biological activity on the Earth's surface (Rowland, 2009) like increasing skin cancer rates.

The Ecoinvent database developed by the Swiss Centre for LCI is used for impact analysis in this study (R; Frischknecht et al., 2007). CML 2001 is an operational guide for the ISO standards that provides impact categories and classification methods for an LCIA (Rolf Frischknecht et al., 2007).

For this case study, CML 2001, Ecoinvent database, and openLCA are applied to quantify the impact categories. Table 9 provides an overview of the impact categories designated for the pump impeller case study impact assessment (Rolf Frischknecht et al., 2007). The impact categories are selected based on the most common environmental impact parameters.

\section{Interpretation of Results}

The overall GWP for the pump impeller of the case study is 3.21 and $3.78 \mathrm{~kg}$ of $\mathrm{CO}_{2}$ for the LMD process and the casting process respectively. This represents a $15 \%$ reduction of $\mathrm{CO}_{2}$ by the LMD process in comparison with the casting process. Figure 5 shows the breakdown of the GWP of each life stage of the pump impeller.
For the LMD process, transportation contributes the most $\mathrm{CO}_{2}$ to the GWP, which is equal to casting. In the premanufacturing stage, LMD consumes more electrical energy compared to casting. This is due to the high SEC required for powder production. LMD process performs better in the manufacturing stage, likely a result of the significant energy required for melting and casting as well as the significant amount of waste. In the last stage of EOL, both processes show the benefits of recyclability, while the LMD process is superior.

The AP of LMD and casting are depicted in Figure 6. Similar to GWP, the pre-manufacturing process for LMD has significantly higher AP than the casting due to the high-energy requirement. The manufacturing stage for casting contains much higher acidification potential resulting from the output waste of the mold and cores. On contrary, the LMD process is more sustainable than casting at the EOL stage. In total, the LMD process contributes $20 \%$ less to AP than casting.

FAETP is illustrated for LMD and casting processes during each life stage in Figure 7. In the pre-manufacturing stage, casting has a higher impact on FAETP because of the sand molding process. Casting FAETP during the manufacturing phase is also much higher than LMD as a result of the significant amount of waste. Overall, the LMD process has 65\% less contribution to FAETP than casting. 


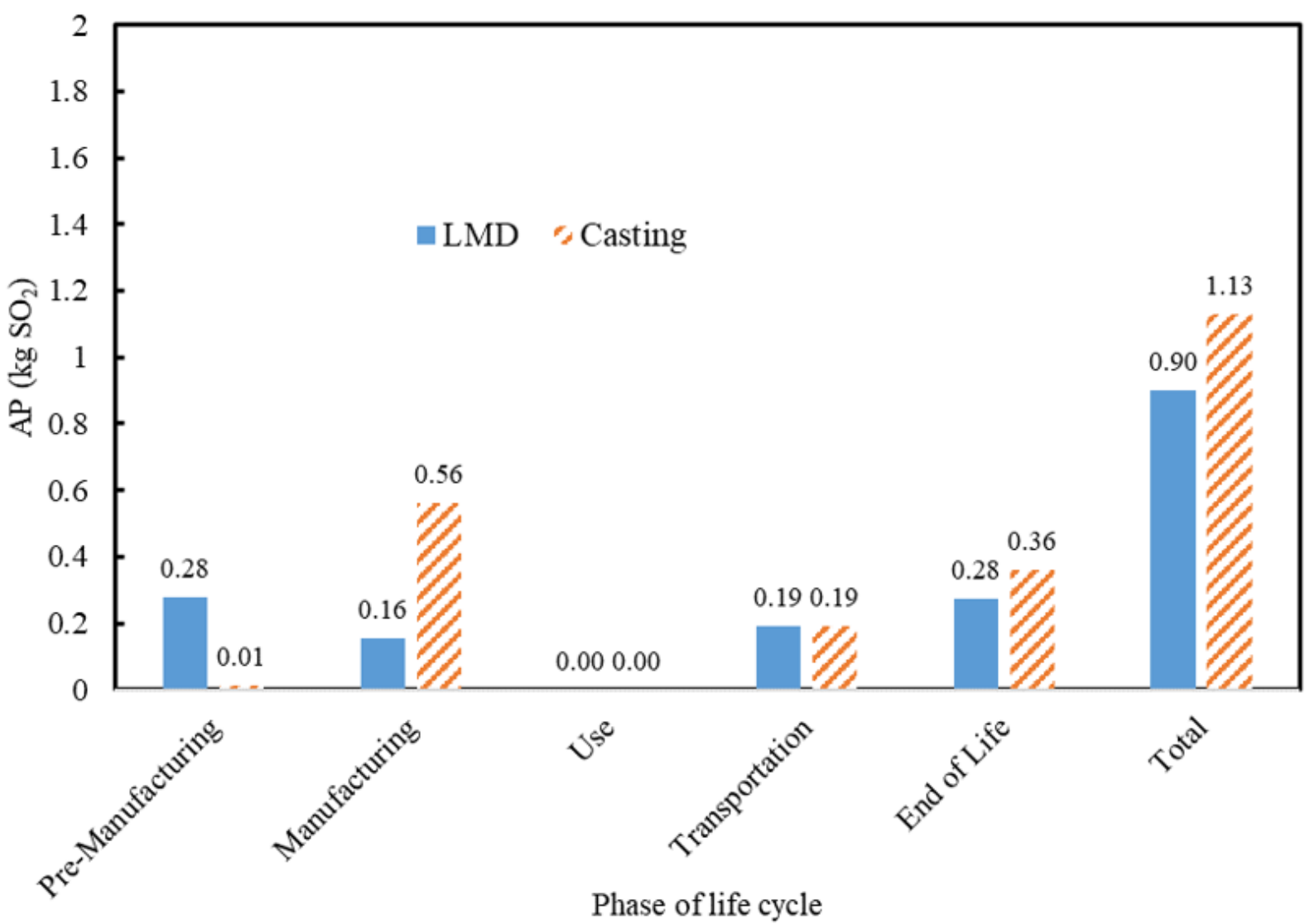

Figure 6. Acidification potential of LMD and casting processes

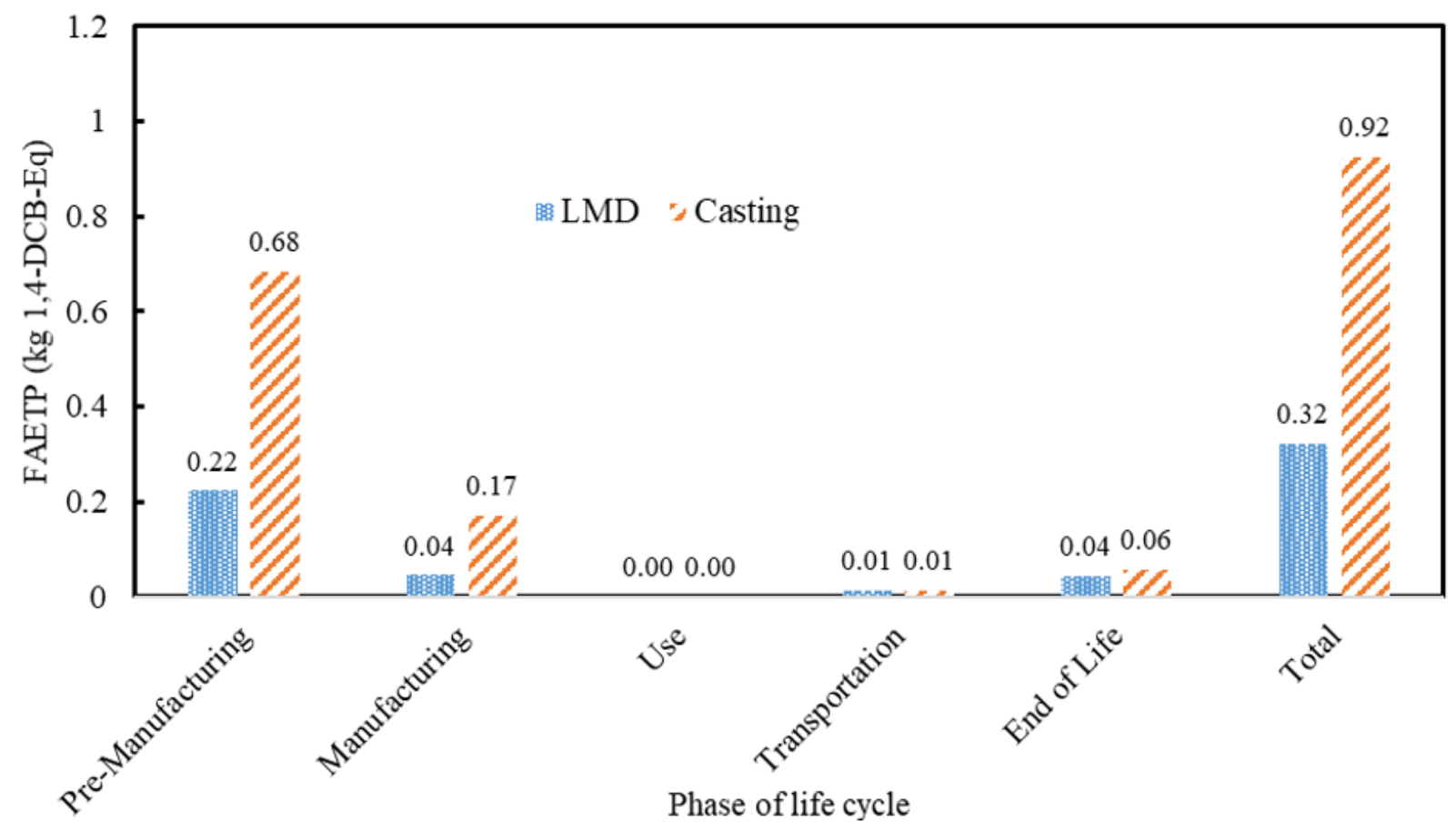

Figure 7. FAETP comparison between LMD and casting processes

HTP for LMD and casting processes in different life stages are shown in Figure 8. The LMD process shows the greatest quantity of HTP in the pre-manufacturing stage, followed by the EOL stage, because of the high electricity consumption required for atomization. The casting process, with its required greensand molds, suffered in the manufacturing process. Transportation has the lowest effect on HTP. Generally, the
LMD process causes a $20 \%$ less impact on HTP in comparison with the casting process.

Figure 9 presents the ODP of LMD and casting processes in various stages. In the pre-manufacturing stage, LMD has a higher effect on ODP than the casting. While at the manufacturing stage, the LMD has much less impact on ODP than casting. It concludes that LMD has a $10 \%$ less impact on ODP in comparison to casting. 


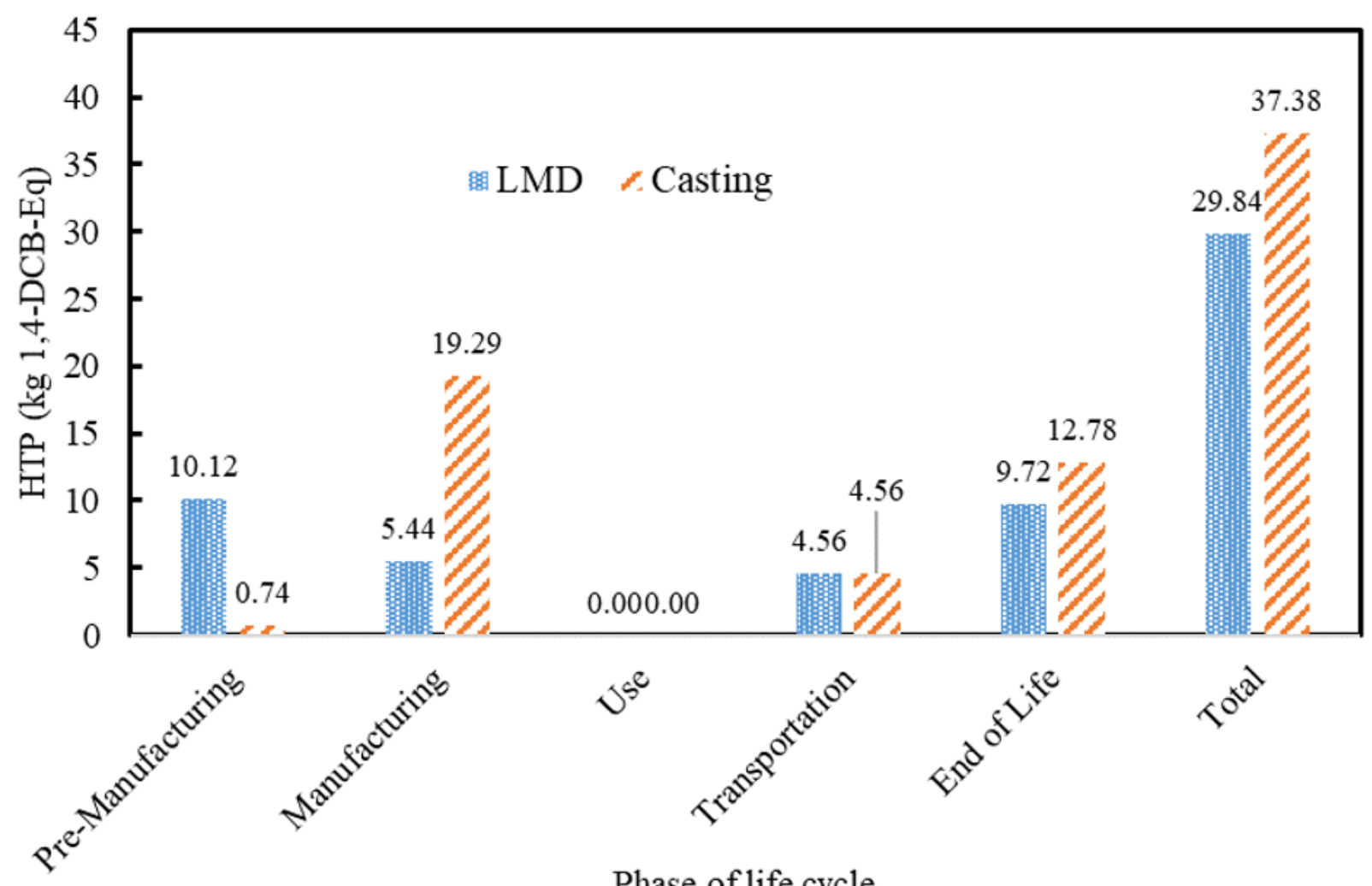

Figure 8. HTP for both LMD and casting processes

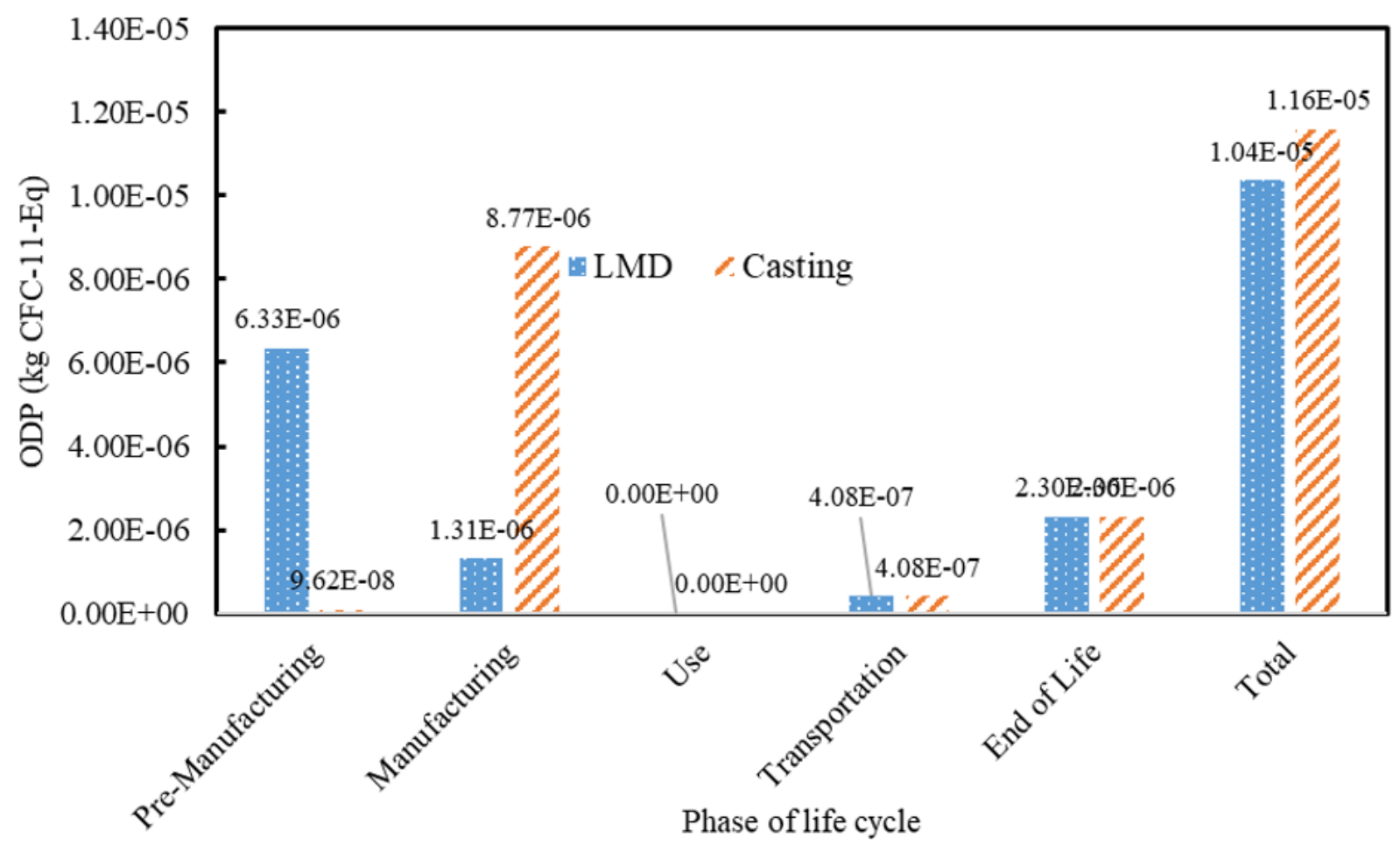

Figure 9. Ozone depletion potential for LMD and casting processes

\section{DISCUSSION OF THE RESULTS}

To show a complete portrait of the AM process, the advantages and disadvantages are compared to a conventional casting process. Before discussing the numerical value of LCA in each process, it should be mentioned that the AM process and casting are closed cycle process from the point of material recyclability as depicted in Figures 3 and 4 . The simulations concluded that LMD environmentally is more sustainable than a casting process. Figure 10 illustrates the percentage reduction of LMD compared to casting in GWP, AP, FAETP, HTP, and ODP.

The intense electricity consumption during the atomization process of powders in the pre-manufacturing stage makes LMD less attractive in comparison to the casting process during this stage. In the other stages, however, there 


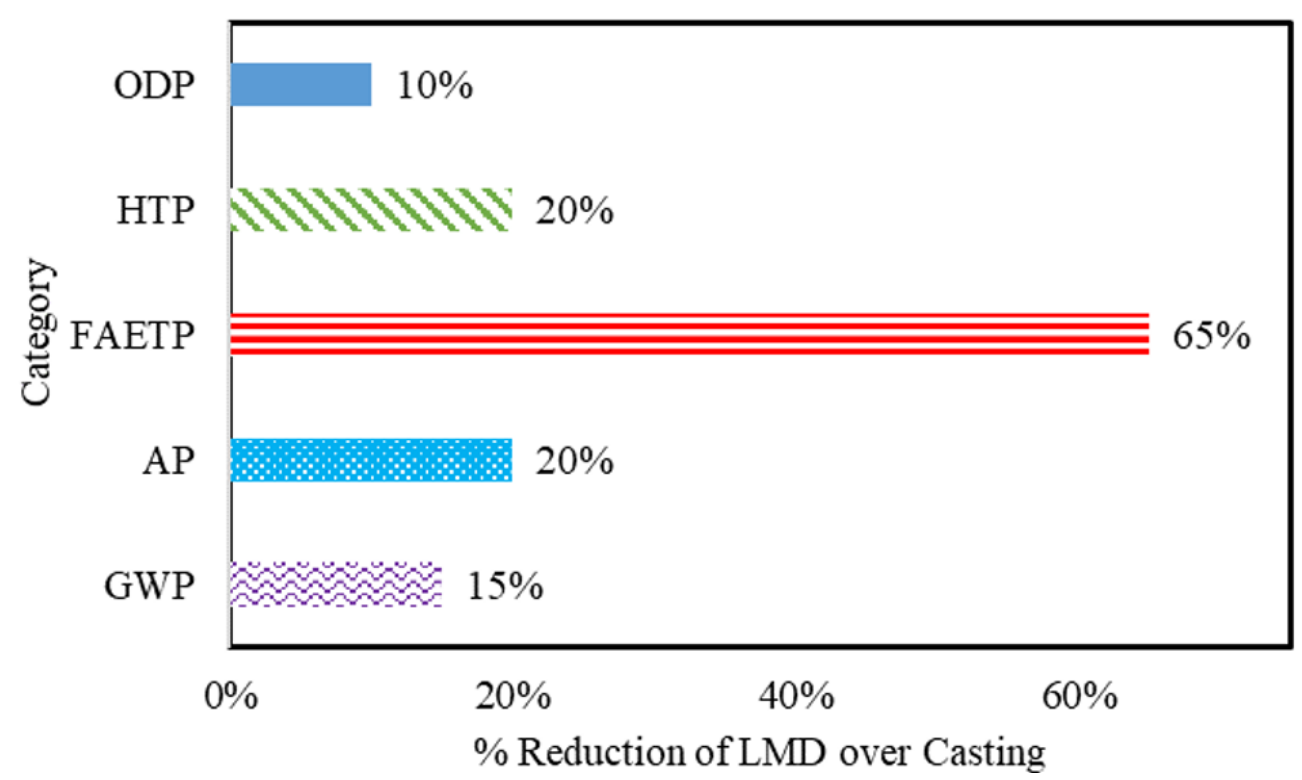

Figure 10. Summary of LMD environmental impact reduction over the casting process

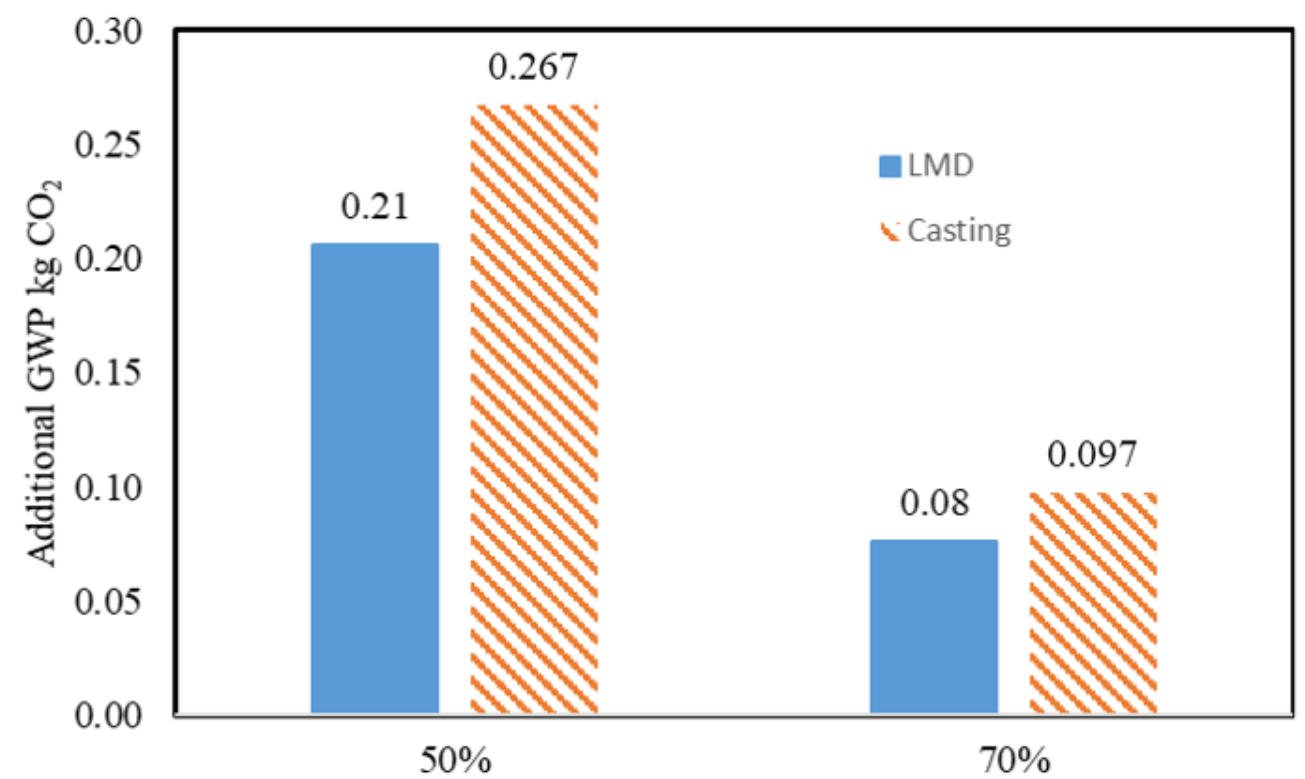

Figure 11. GWP increases resulting from decreased recycling rates

was a strong indication that LMD is more environmentally friendly. For further improvement, the authors suggest using electricity generated from renewable energy resources and hydroelectricity to lessen the environmental impact of the LMD on the environment during pre-manufacturing, manufacturing, and EOL. However, this is not the ultimate solution for improving the LMD process. Finding new methods to lower electricity demand as well as achieve higher build-up rates for the manufacturing stage are permanents solutions for enhancing the LMD.

The size of the laser and build-up rate of the machine depends on the manufacturer, and therefore, it accounts for a large change in total energy required for the manufacturing process. The large difference in SEC for powder production is an interesting fact. The build-up rate, powder size, SEC of powder consumption, powder type, and powder utilization efficiency influence the LCA of the AM process. In particular, the SEC of the atomization process was found to be highly variable. $6.60 \mathrm{kWh} / \mathrm{kg}$ was used for this LCA, yet in literature, it is reported as a range for steel from $4.2 \mathrm{kWh} / \mathrm{kg}$ to $7.2 \mathrm{kWh} / \mathrm{kg}$ (Kellens et al., 2017).

The results of this case study also support the above literature review regarding the environmental aspects of the AM technology. Furthermore, some of the shortcomings of the AM technology are illustrated in pre-manufacturing and manufacturing stages that lead us to future research on the advancement of the AM technology toward environmental sustainability.

\section{Sensitivity Test}

Recycling rates of 50\% and 70\% are shown in Figure 12 for both processes. The values indicate the increased GWP resulting from additional virgin resources being required to make up for the decreased recycling rates. For example, a 70\% recycling rate would result in an increase of GWP of 0.08 for 


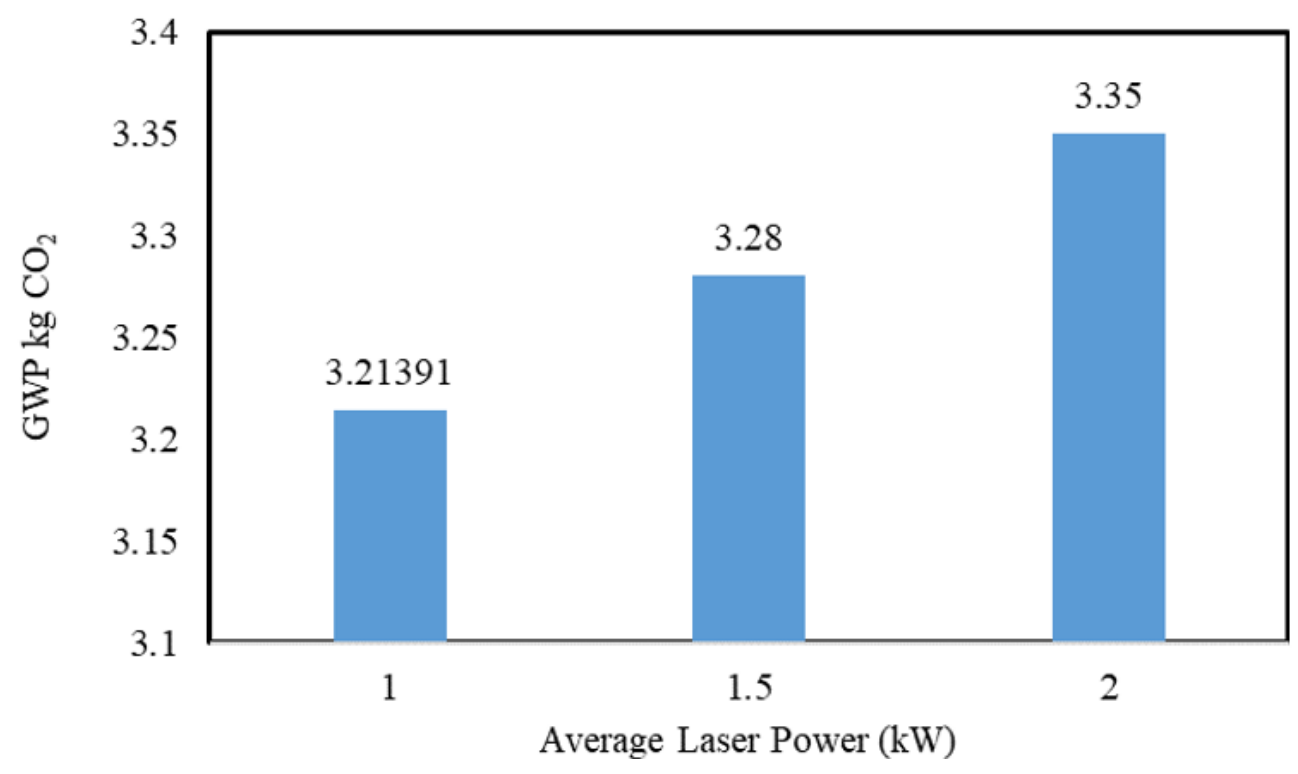

Figure 12. Laser power impact on GWP

Table 10. Results comparison

\begin{tabular}{ccccccc}
\hline & Built Rate $\mathbf{( k g / h )}$ & Laser $(\mathbf{k W})$ & SEC (kWh/kg) & Powder Efficiency (\%) & Environmental Impact Indicators & Outcome \\
\hline This study & 0.3 & 1 & 6.6 & 90 & GWP, AP, FAETP, HTP, ODP & AM Superior \\
\hline Peng et al. & 0.47 & 1 & 0.6 & 92.5 & GWP, AP, CADP, RI & AM Superior \\
\hline
\end{tabular}

the LMD process since the required material would have to be obtained from the pre-manufacturing process again.

A similar sensitivity analysis on the average laser power shows increased GWP if the average power is increased. Figure 12 shows the total GWP if the laser power is $1 \mathrm{~kW}, 1.5 \mathrm{~kW}$, or 2 $\mathrm{kW}$. The selected laser powers are among applicable power for production of steel using SLM technology.

\section{VALIDATION}

Other similar case studies were investigated to validate the outcomes of the study. Peng et al. experimented with the fabrication of an impeller applied in turbomachines with AM and casting processes (Peng et al., 2017). Their results showed that the environmental impact through indicators of GWP, AP, Chinese resource depletion potential (CADP), and respiratory inorganics (RI) was much lower in the $\mathrm{AM}$ process in comparison with casting. Table 10 compares the findings from this study with the one reported by Peng et al. for AM processed case studies. In the present study, AM is superior by 10 to $65 \%$ less environmental impact compared with casting. Peng et al. showed similar superiority for AM with a shorter range. Both studies show the superiority of the AM process to traditional methods. Considering the variability of many different parameters in the LMD process, such as build rate, powder size, SEC of powder consumption, and materials utilization efficiency, the authors believe the results of the case study presented in this study are in acceptable agreement with the similar studies.

\section{CONCLUSIONS}

Due to the potential environmental impacts resulting from $\mathrm{AM}$, the effects of the process need more investigation. There is no need for expensive molding or different stages of machining in the AM process, which presents a beneficial economical advantage while lowering harmful contribution to the environment through fewer operations, fewer materials, and reduced transportation. The most desirable characteristics of the AM process are its recyclability, the possibility of reusing feedstock materials, and its high material efficiency. Recycling the waste powders during the AM process and at EOL make AM an attractive technology. To compare the AM process with the conventional processes, the fabrication of a pump impeller was simulated in this study for LMD as a well-known AM process and casting process. The outcomes indicated that in the pre-manufacturing stage, the AM process has a higher environmental impact compared to casting. This was attributed to the intense electricity consumption required for the atomization process. In the manufacturing stage, LMD was superior to casting due to its low waste. Although it was favorable to casting, the low speed of the AM process increases the total energy used. Different laser power was explored and found to have little effect on environmental effects. An increase in average power from $1 \mathrm{~kW}$ to $1.5 \mathrm{~kW}$ increased the GWP by only $2 \%$. Ultimately, a pump impeller produced by LMD has anywhere from $10 \%$ to $65 \%$ less impact on the environment depending upon the impact category. In conclusion, the recyclability of the AM process has the greatest advantage from point of environmental protection. Although there are some weaknesses in the pre-manufacturing and manufacturing stages that cause greater strain on the environment, these weaknesses are mitigated by using electricity generated from hydro resources and renewable 
energy. Renewable energy sources have lower GWP and AP compared to fossil fuels, and their use may help offset the intense energy demand of LMD. The future work needs to be focused on improving the sustainability of AM technology in developing powders manufacturing technologies with lower energy consumption, investigating the impact of dominant parameters (SEC, built rate, powders efficiency, etc.) on the LCA of the AM process, optimization of key parameters for the efficient outcome, and increasing the production speed of the AM process during manufacturing. This will advance the economics of the AM process as well by making it less expensive to construct the required parts.

Author contributions: All co-authors have involved in all stages of this study while preparing the final version. They all agree with the results and conclusions.

Funding: Authors appreciate the SMART fund by the US NAVY for supporting the graduate study.

Declaration of interest: The authors declare that they have no competing interests.

Ethics approval and consent to participate: Not applicable.

Availability of data and materials: All data generated or analyzed during this study are available for sharing when appropriate request is directed to corresponding author.

\section{REFERENCES}

ASTM F2792: Standard Terminology for Additive Manufacturing Technologies (No. 12a), 2013.

Azarmi, F. and Sevostianov, I. (2020). Evaluation of the residual stresses in metallic materials produced by additive manufacturing technology: effect of microstructure. Current Opinion in Chemical Engineering, 28, 21-27. https://doi.org/10.1016/j.coche.2019.12.004

Baumers, M., Dickens, P., Tuck, C. and Hague, R. (2016). The cost of additive manufacturing: machine productivity, economies of scale and technology-push. Technological Forecasting and Social Change, 102, 193-201. https://doi.org/10.1016/J.TECHFORE.2015.02.015

Bekker, A. C. M. and Verlinden, J. C. (2018). Life cycle assessment of wire + arc additive manufacturing compared to green sand casting and CNC milling in stainless steel. Journal of Cleaner Production, 177, 438-447. https://doi.org/10.1016/j.jclepro.2017.12.148

Berman, B. (2012). 3-D printing: The new industrial revolution. Business Horizons, 55, 155-162. https://doi.org/10.1016/J.BUSHOR.2011.11.003

Böckin, D. and Tillman, A. M. (2019). Environmental assessment of additive manufacturing in the automotive industry. Journal of Cleaner Production, 226, 977-987. https://doi.org/10.1016/j.jclepro.2019.04.086

Catlin, J. R. and Wang, Y. (2013). Recycling gone bad: When the option to recycle increases resource consumption. Journal of Consumer Psychology, 23, 122-127. https://doi.org/10.1016/J.JCPS.2012.04.001

Chan, J. K. H. (2016). The ethics of working with wicked urban waste problems: The case of Singapore's Semakau Landfill. Landscape and Urban Planning, 154, 123-131. https://doi.org/10.1016/J.LANDURBPLAN.2016.03.017
Chen, D., Heyer, S., Ibbotson, S., Salonitis, K., Steingrímsson, J. G. and Thiede, S. (2015). Direct digital manufacturing: definition, evolution, and sustainability implications. Journal of Cleaner Production, 107, 615-625. https://doi.org/10.1016/J.JCLEPRO.2015.05.009

DebRoy, T., Wei, H. L., Zuback, J. S., Mukherjee, T., Elmer, J. W., et al. (2018). Additive manufacturing of metallic components - Process, structure and properties. Progress in Material Science, 92, 112-224. https://doi.org/10.1016/J.PMATSCI.2017.10.001

Despeisse, M., Yang, M., Evans, S., Ford, S. and Minshall, T. (2017). Sustainable Value Roadmapping Framework for Additive Manufacturing. Procedia CIRP, 61, 594-599. https://doi.org/10.1016/j.procir.2016.11.186

Ding, D., Pan, Z., Cuiuri, D. and Li, H. (2015). Wire-feed additive manufacturing of metal components: technologies, developments and future interests. The International Journal of Advanced Manufacturing Technology, 81, 465-481. https://doi.org/10.1007/s00170015-7077-3

epa.gov, 1992. 1,4-Dichlorobenzene (para-Dichlorobenzene).

Faludi, J., Baumers, M., Maskery, I. and Hague, R. (2017). Environmental impacts of selective laser melting: Do printer, powder, or power dominate? Journal of Industrial Ecology, 21, S144-S156. https://doi.org/10.1111/jiec.12528

Faludi, J., Bayley, C., Bhogal, S. and Iribarne, M. (2015). Comparing environmental impacts of additive manufacturing vs traditional machining via life-cycle assessment. Rapid Prototyping Journal, 21(1), 14-33. https://doi.org/10.1108/RPJ-07-2013-0067

Ford, S. and Despeisse, M. (2016). Additive manufacturing and sustainability: an exploratory study of the advantages and challenges. Journal of Cleaner Production, 137, 1573-1587. https://doi.org/10.1016/J.JCLEPRO.2016.04.150

Frazier, W. E. (2014). Metal Additive Manufacturing: A Review. Journal of Materials Engineering and Performance, 23, 19171928. https://doi.org/10.1007/s11665-014-0958-z

Frischknecht, R., Jungbluth, N., Althaus, H.-J., Bauer, C., Doka, G., et al. (2007). Swiss centre for life cycle inventories a joint initiative of the ETH domain and Swiss Federal Offices implementation of life cycle impact assessment methods data v2.0.

Frischknecht, R., Jungbluth, N., Althaus, H.-J., Hischier, R., Doka, G., et al. (2007). Overview and methodology. Data v2.0. Ecoinvent report No. 1 (Technical Report) | ETDEWEB.

Fröhlich, P., Lorenz, T., Martin, G., Brett, B. and Bertau, M. (2017). Valuable metals-recovery processes, current trends, and recycling strategies. Angewandte Chemie International Edition, 56(10), 2544-2580. https://doi.org/10.1002/anie.201605417

Fullenwider, B., Kiani, P., Schoenung, J. M. and Ma, K. (2019). Two-stage ball milling of recycled machining chips to create an alternative feedstock powder for metal additive manufacturing. Powder Technology, 342, 562-571. https://doi.org/10.1016/J.POWTEC.2018.10.023 
Gebler, M., Schoot Uiterkamp, A. J. M. and Visser, C. (2014). A global sustainability perspective on 3D printing technologies. Energy Policy, 74, 158-167. https://doi.org/10.1016/J.ENPOL.2014.08.033

Graedel, T. E., Allwood, J., Birat, J.-P., Buchert, M., Hagelüken, C., et al. (2011). What do we know about metal recycling rates? Journal of Industrial Ecology, 15, 355-366. https://doi.org/10.1111/j.1530-9290.2011.00342.x

Gu, D. D., Meiners, W., Wissenbach, K. and Poprawe, R. (2012). Laser additive manufacturing of metallic components: materials, processes and mechanisms. International Material Reviews, 57, 133-164. https://doi.org/10.1179/ 1743280411Y.0000000014

Herzog, D., Seyda, V., Wycisk, E. and Emmelmann, C. (2016). Additive manufacturing of metals. Acta Materialia, 117, 371-392. https://doi.org/10.1016/J.ACTAMAT.2016.07.019

Huang, S. H., Liu, P., Mokasdar, A. and Hou, L. (2012). Additive manufacturing and its societal impact: A literature review. The International Journal of Advanced Manufacturing Technology, 67, 1191-1203. https://doi.org/10.1007/ s00170-012-4558-5

Johnson, J., Reck, B. K., Wang, T. and Graedel, T. E. (2008). The energy benefit of stainless steel recycling. Energy Policy 36, 181-192. https://doi.org/10.1016/J.ENPOL.2007.08.028

Jolliet, O., Margni, M., Charles, R., Humbert, S., Payet, J., et al. (2003). IMPACT 2002+: A new life cycle impact assessment methodology. The International Journal of Life Cycle Assessment, 8, 324-330. https://doi.org/10.1007/ BF02978505

Kellens, K., Baumers, M., Gutowski, T. G., Flanagan, W., Lifset, R. and Duflou, J. R. (2017). Environmental dimensions of additive manufacturing: Mapping application domains and their environmental implications. Journal of Industrial Ecology, 21(S1), S49-S68.https://doi.org/10.1111/jiec.12629

Kellens, K., Renaldi, R., Dewulf, W., Kruth, J. and Duflou, J. R. (2014). Environmental impact modeling of selective laser sintering processes. Rapid Prototyping Journal, 20, 459-470. https://doi.org/10.1108/RPJ-02-2013-0018

Kosai, S. and Yamasue, E. (2019). Global warming potential and total material requirement in metal production: Identification of changes in environmental impact through metal substitution. Science of the Total Environment, 651(Part 2), 1764-1775. https://doi.org/10.1016/ J.SCITOTENV.2018.10.085

LCA data | openLCA.org.

Le, V. T., Paris, H. and Mandil, G. (2017). Process planning for combined additive and subtractive manufacturing technologies in a remanufacturing context. J. Manuf. Syst. 44, 243-254. https://doi.org/10.1016/J.JMSY.2017.06.003

Levy, G. N., Schindel, R. and Kruth, J. P. (2003). Rapid manufacturing and rapid tooling with layer manufacturing (LM) technologies, state of the art and future perspectives. CIRP Annals - Manufacturing Technology, 52(2), 589-609. https://doi.org/10.1016/S0007-8506(07)60206-6
Leyens, C. and Beyer, E. (2014). Innovations in laser cladding and direct laser metal deposition. In Laser Surface Engineering: Processes and Applications, pp. 181-192. https://doi.org/10.1016/B978-1-78242-074-3.00008-8

Mami, F., Revéret, J. P., Fallaha, S. and Margni, M., 2017. Evaluating Eco-Efficiency of 3D Printing in the Aeronautic Industry. Journal of Industrial Ecology, 21(S1), S37-S48. https://doi.org/10.1111/jiec.12693

Morrow, W. R., Qi, H., Kim, I., Mazumder, J. and Skerlos, S. J. (2007). Environmental aspects of laser-based and conventional tool and die manufacturing. Journal of Cleaner Production, 15, 932-943. https://doi.org/10.1016/ J.JCLEPRO.2005.11.030

Oettmeier, K. and Hofmann, E. (2016). Impact of additive manufacturing technology adoption on supply chain management processes and components. Journal of Manufacturing Technology Management, 27, 944-968. https://doi.org/10.1108/JMTM-12-2015-0113

Paris, H., Mokhtarian, H., Coatanéa, E., Museau, M. and Ituarte, I. F. (2016). Comparative environmental impacts of additive and subtractive manufacturing technologies. CIRP Annals, 65, 29-32. https://doi.org/10.1016/J.CIRP.2016.04. 036

Peng, S., Li, T., Wang, X., Dong, M., Liu, Z., Shi, J. and Zhang, H. (2017). Toward a sustainable impeller production: Environmental impact comparison of different impeller manufacturing methods. Journal of Industrial Ecology, 21, S216-S229. https://doi.org/10.1111/jiec.12628

Peng, T., Kellens, K., Tang, R., Chen, C. and Chen, G. (2018). Sustainability of additive manufacturing: An overview on its energy demand and environmental impact. Additive Manufacturing, 21, 694-704. https://doi.org/10.1016/ J.ADDMA.2018.04.022

Pertsova, C. C. (2007). Ecological economics research trends. Nova Science Publishers.

Petrovic, V., Vicente Haro Gonzalez, J., Jordá Ferrando, O., Delgado Gordillo, J., Ramón Blasco Puchades, J. and Portolés Griñan, L. (2011). Additive layered manufacturing: sectors of industrial application shown through case studies. International Journal of Production Research, 49, 1061-1079. https://doi.org/10.1080/ 00207540903479786

Pinkerton, A. J. (2016). Lasers in additive manufacturing. Optics \& Laser Technology, 78, 25-32. https://doi.org/10.1016/J.OPTLASTEC.2015.09.025

Pinkerton, A. J. and Li, L. (2003). Rapid prototyping using direct laser deposition-the effect of powder atomization type and flowrate. Proceedings of the Institution of Mechanical Engineers, Part B: Journal of Engineering Manufacture, 217(6), 741-752. https:/doi.org/10.1243/ 09544050360673134

Rebitzer, G., Ekvall, T., Frischknecht, R., Hunkeler, D., Norris, G., et al. (2004). Life cycle assessment: Part 1: Framework, goal and scope definition, inventory analysis, and applications. Environment International, 30(5), 701-720. https://doi.org/10.1016/J.ENVINT.2003.11.005 
Renou, S., Thomas, J. S., Aoustin, E. and Pons, M. N. (2008). Influence of impact assessment methods in wastewater treatment LCA. Journal of Cleaner Production, 16, 10981105. https://doi.org/10.1016/J.JCLEPRO.2007.06.003

Rosenbaum, R. K., Bachmann, T. M., Gold, L. S., Huijbregts, M. A. J., Jolliet, O., et al. (2008). USEtox-the UNEP-SETAC toxicity model: recommended characterisation factors for human toxicity and freshwater ecotoxicity in life cycle impact assessment. The International Journal of Life Cycle Assessment, 13, 532-546. https://doi.org/10.1007/s11367008-0038-4

Rowland, F. S. (2009). Stratospheric Ozone Depletion, in: Twenty Years of Ozone Decline. Springer Netherlands, Dordrecht, pp. 23-66. https://doi.org/10.1007/978-90-4812469-5_5

Ryding, S.-O. (1999). ISO 14042 Environmental management, Life cycle assessment, Life cycle impact assessment. International Journal of Life Cycle Assessment, 4, 307-307. https://doi.org/10.1007/BF02978514

Salonitis, K., Jolly, M. R., Zeng, B. and Mehrabi, H. (2016). Improvements in energy consumption and environmental impact by novel single shot melting process for casting. Journal of Cleaner Production, 137, 1532-1542. https://doi.org/10.1016/j.jclepro.2016.06.165

Seifi, M., Salem, A., Beuth, J., Harrysson, O. and Lewandowski, J. J. (2016). Overview of materials qualification needs for metal additive manufacturing. JOM, 68, 747-764. https://doi.org/10.1007/s11837-015-1810-0

Selcuk, C. (2011). Laser metal deposition for powder metallurgy parts. Powder Metallurgy, 54(2), 94-99. https://doi.org/10.1179/174329011X12977874589924

Serres, N., Tidu, D., Sankare, S. and Hlawka, F. (2011). Environmental comparison of MESO-CLAD ${ }^{\circledR}$ process and conventional machining implementing life cycle assessment. Journal of Cleaner Production, 19, 1117-1124. https://doi.org/10.1016/J.JCLEPRO.2010.12.010

Shamsaei, N., Yadollahi, A., Bian, L., Thompson, S.M., 2015. An overview of Direct Laser Deposition for additive manufacturing; Part II: Mechanical behavior, process parameter optimization and control. Additive Manufacturing, 8, 12-35. https://doi.org/10.1016/ J.ADDMA.2015.07.002

Sreenivasan, R., Goel, A. and Bourell, D. L. (2010). Sustainability issues in laser-based additive manufacturing. Physics Procedia, 5(Part A), 81-90. https://doi.org/10.1016/J.PHPRO.2010.08.124

Srivatsan, T. S. and Sudarshan, T. S. (2015). Additive manufacturing innovations, Advances, and Applications, 1st ed. CRC Press. https://doi.org/10.1201/b19360

Stock, T. and Seliger, G. (2016). Opportunities of sustainable manufacturing in Industry 4.0. Procedia CIRP, 40, 536-541. https://doi.org/10.1016/J.PROCIR.2016.01.129
Sun, Z., Xiao, Y., Agterhuis, H., Sietsma, J. and Yang, Y. (2016). Recycling of metals from urban mines - a strategic evaluation. Journal of Cleaner Production, 112, 2977-2987. https://doi.org/10.1016/J.JCLEPRO.2015.10.116

Sverdrup, H. U., Ragnarsdottir, K. V. and Koca, D. (2017). An assessment of metal supply sustainability as an input to policy: security of supply extraction rates, stocks-in-use, recycling, and risk of scarcity. Journal of Cleaner Production, 140, 359-372. https://doi.org/10.1016/J.JCLEPRO.2015.06. 085

Thompson, S. M., Bian, L., Shamsaei, N. and Yadollahi, A. (2015). An overview of direct laser deposition for additive manufacturing; Part I: Transport phenomena, modeling and diagnostics. Additive Manufacturing, 8, 36-62. https://doi.org/10.1016/J.ADDMA.2015.07.001

Tofail, S. A. M., Koumoulos, E. P., Bandyopadhyay, A., Bose, S., O’Donoghue, L. and Charitidis, C. (2018). Additive manufacturing: scientific and technological challenges, market uptake and opportunities. Materials Today, 21(1), 22-37. https://doi.org/10.1016/J.MATTOD.2017.07.001

Torres-Carrillo, S., Siller, H. R., Vila, C., López, C. and Rodríguez, C. A. (2020). Environmental analysis of selective laser melting in the manufacturing of aeronautical turbine blades. Journal of Cleaner Production, 246, 119068. https://doi.org/10.1016/j.jclepro.2019.119068

US EPA, Understanding Global Warming Potentials. epa.gov. Available at: https:/www.epa.gov/ghgemissions/ understanding-global-warming-potentials

Villamil, C., Nylander, J., Hallstedt, S. I., Schulte, J. and Watz, M. (2018). Additive manufacturing from a strategic sustainability perspective. In International Design Conference Design 2018. https://doi.org/10.21278/ idc. 2018.0353

Walachowicz, F., Bernsdorf, I., Papenfuss, U., Zeller, C., Graichen, A., et al. (2017). Comparative energy, resource and recycling lifecycle analysis of the industrial repair process of gas turbine burners using conventional machining and additive manufacturing. Journal of Industrial Ecology, 21, 205-215. https://doi.org/10.1111/ jiec. 12637

Yadroitsev, I., Krakhmalev, P., Yadroitsava, I., Johansson, S. and Smurov, I. (2013). Energy input effect on morphology and microstructure of selective laser melting single track from metallic powder. Journal of Materials Processing Technology, 213(4), 606-613. https://doi.org/10.1016/ J.JMATPROTEC.2012.11.014

Yakout, M., Elbestawi, M. A. and Veldhuis, S. C. (2018). A review of metal additive manufacturing technologies. Solid State Phenomena, 278, 1-14. https://doi.org/10.4028/ www.scientific.net/SSP.278.1

Yilmaz, O., Anctil, A. and Karanfil, T. (2015). LCA as a decision support tool for evaluation of best available techniques (BATs) for cleaner production of iron casting. Journal of Cleaner Production, 105, 337-347. https://doi.org/10.1016/ J.JCLEPRO.2014.02.022 